\title{
2021 Focused Update Consensus Guidelines of the Asia Pacific Heart Rhythm Society on Stroke Prevention in Atrial Fibrillation: Executive Summary*
}

\author{
Tze-Fan Chao ${ }^{1,2}$ Boyoung Joung ${ }^{3}$ Yoshihide Takahashi ${ }^{4}$ Toon Wei Lim ${ }^{5}$ Eue-Keun Choi ${ }^{6}$ \\ Yi-Hsin Chan ${ }^{7,8,9}$ Yutao Guo ${ }^{10}$ Charn Sriratanasathavorn ${ }^{11}$ Seil Oh ${ }^{6}$ Ken Okumura ${ }^{12}$ \\ Gregory Y. H. Lip ${ }^{13,14,0}$
}

${ }^{1}$ Division of Cardiology, Department of Medicine, Taipei Veterans General Hospital, Taipei, Taiwan

2 Institute of Clinical Medicine and Cardiovascular Research Center, National Yang Ming Chiao Tung University, Taipei, Taiwan

${ }^{3}$ Division of Cardiology, Department of Internal Medicine, Yonsei

University College of Medicine, Seoul, Republic of Korea

${ }^{4}$ The Department of Advanced Arrhythmia Research, Tokyo Medical and Dental University, Tokyo, Japan

${ }^{5}$ National University Heart Centre, National University Hospital, Singapore

${ }^{6}$ Department of Internal Medicine, Seoul National University Hospital, Seoul, Republic of Korea

${ }^{7}$ Microscopy Core Laboratory, Chang Gung Memorial Hospital, Linkou, Taoyuan, Taiwan

${ }^{8}$ College of Medicine, Chang Gung University, Taoyuan, Taiwan

Address for correspondence Tze-Fan Chao, MD, PhD, Division of Cardiology, Department of Medicine, Taipei Veterans General Hospital, No. 201, Sec. 2, Shih-Pai Road, Taipei 112, Taiwan (e-mail: eyckeyck@gmail.com).

\footnotetext{
${ }^{9}$ Microscopy Core Laboratory, Chang Gung Memorial Hospital, Linkou, Taoyuan, Taiwan

${ }^{10}$ Pulmonary Vessel and Thrombotic Disease, Chinese PLA General Hospital, Beijing, China

${ }^{11}$ Her Majesty Cardiac Center, Siriraj, Thailand

12 Division of Cardiology, Saiseikai Kumamoto Hospital, Kumamoto, Japan

${ }^{13}$ Liverpool Centre for Cardiovascular Science, University of Liverpool \& Liverpool Heart and Chest Hospital, Liverpool, United Kingdom

${ }^{14}$ Aalborg Thrombosis Research Unit, Department of Clinical Medicine, Aalborg University, Aalborg, Denmark
}

Thromb Haemost 2022;122:20-47.
Abstract
Keywords
- APHRS
- atrial fibrillation
- stroke prevention
- consensus guidelines
- executive summary

The consensus of the Asia Pacific Heart Rhythm Society (APHRS) on stroke prevention in atrial fibrillation (AF) has been published in 2017 which provided useful clinical guidance for cardiologists, neurologists, geriatricians, and general practitioners in the Asia-Pacific region. In these years, many important new data regarding stroke prevention in AF were reported. The practice guidelines subcommittee members comprehensively reviewed updated information on stroke prevention in AF, and summarized them in this 2021 focused update of the 2017 consensus guidelines of the APHRS on stroke prevention in AF. We highlighted and focused on several issues, including the importance of the AF Better Care pathway, the advantages of non-vitamin $\mathrm{K}$ antagonist oral anticoagulants (NOACs) for Asians, the considerations of use of NOACs for Asian AF patients with single one stroke risk factor beyond gender, the role of lifestyle factors on stroke risk, the use of oral anticoagulants during the "coronavirus disease 2019" pandemic, etc. We fully realize that there are gaps, unaddressed questions, and many areas of uncertainty and debate in the current knowledge of AF, and the physician's decision remains the most important factor in the management of AF.

\footnotetext{
This is an executive summary of the full consensus guideline, which is published in Journal of Arrhythmia by Chao et al. ${ }^{6}$ Note: The review process for this paper was fully handled by Christian Weber, Editor-in-Chief.
}

received

October 15, 2021 accepted after revision October 20, 2021

published online

November 13, 2021
DOI https://doi.org/ $10.1055 / \mathrm{s}-0041-1739411$. ISSN $0340-6245$.

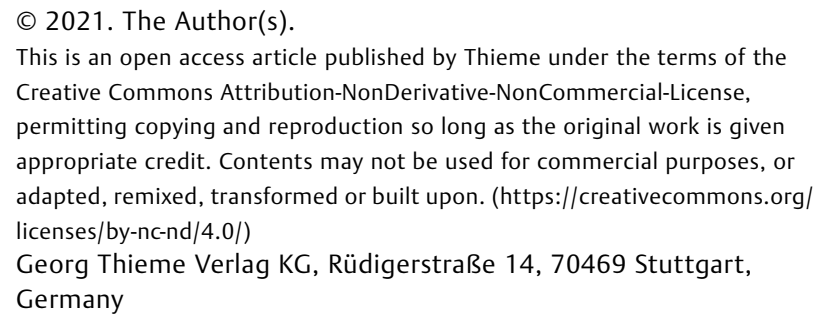




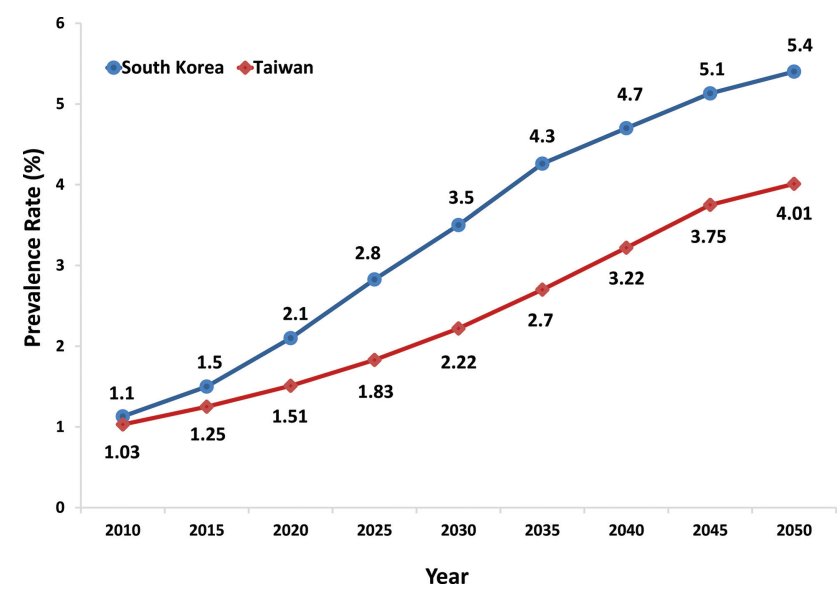

Fig. 1 Projected prevalence of AF in Taiwan and South Korea. Data used in the figure were adapted from Chao et al and Kim et al. ${ }^{2,3} \mathrm{AF}$, atrial fibrillation.

\section{Epidemiology of AF and Risk of AF-Related Stroke}

Atrial fibrillation (AF) is a global problem, with an increasing incidence and prevalence with an aging population. ${ }^{1}$ Similar to Western countries, the prevalence rates of AF will continuously increase in the following decades, which are projected to be $4.0 \%$ in Taiwan and $5.4 \%$ in South Korea in year 2050 (-Fig. 1) $)^{2,3}$

For Asian AF patients, the annual risk of ischemic stroke is around 3.0\% (1.60-4.95\%) based on the pooled analysis of eight studies. ${ }^{4}$ Importantly, the 1-year risk of ischemic stroke after newly diagnosed AF was similar from year 2000 (4.45\%) to $2010(3.95 \%)^{2}$ and gradually decreasing in the era of nonvitamin $\mathrm{K}$ antagonist (non-VKA) oral anticoagulants (NOACs). ${ }^{5}$ The observed reduction in stroke risk may be contributed to the increasing initiation rates of oral anticoagulants (OACs) in newly diagnosed AF patients, which significantly increased from 13.6 to $35.6 \%$, contemporaneous with the introduction of NOACs (-Fig. 2). ${ }^{5}$

This is an executive summary of the 2021 focused update of the 2017 consensus guidelines of the Asia-Pacific Heart Rhythm Society (APHRS) on stroke prevention in AF. The full document has been published in Journal of Arrhythmia ${ }^{6}$ and includes further details of the evidence/data pertaining to the recommendations made in these guidelines.

\section{The Importance of Integrated or Holistic Care in Managing Patients with AF: Impact on Stroke Risk Reduction and Adverse Outcomes in AF}

Since AF patients usually had multiple comorbidities, a more holistic and integrated approach to $\mathrm{AF}$ management has been proposed to improve clinical outcomes in patients with $\mathrm{AF}^{7}$

This integrated approach is directed at stroke prevention, better symptom management, and to tackle other cardiovascular risk factors/comorbidities (e.g., hypertension) aimed to reduce AF-related mortality, morbidity, and hospitalizations.
This can streamline decision-making for a holistic approach to $\mathrm{AF}$ management in an integrated manner, proposed as the ABC (Atrial fibrillation Better Care) pathway ( - Fig. $\mathbf{3}^{7}$ :

- "A": Avoid stroke with anticoagulation, i.e., well-managed warfarin (time in therapeutic range [TTR] $>65-70 \%$ ) or NOACs. NOACs are recommended in preference to warfarin for NOAC-eligible AF patients.

- "B": Better symptom management with patient-centered symptom-directed decisions for rate or rhythm control.

- " $\mathrm{C}$ ": Cardiovascular risk and comorbidity management (blood pressure [BP] control, heart failure, cardiac ischemia, sleep apnea, etc.) as well as lifestyle changes (obesity reduction, regular exercise, reducing alcohol/stimulants, psychological morbidity, etc.).

With the focus on patient-centered management, explanation using the simple $\mathrm{ABC}$ concept can also lead to improved understanding and disease awareness amongst patients, better knowledge about their condition, and the priorities of management. Different health care professionals managing the $\mathrm{AF}$ patient can also discuss the management based on the $A, B$, and $C$ pillars of the $A B C$ pathway.

A systematic review and meta-analysis showed a lower risk of all-cause death (odds ratio [OR]: $0.42,95 \%$ confidence interval [CI]: 0.31-0.56), cardiovascular death (OR: 0.37, 95\% CI: $0.23-0.58$ ), stroke (OR: $0.55,95 \% \mathrm{CI}: 0.37-0.82$ ), and major bleeding (OR: $0.69,95 \% \mathrm{CI}$ : 0.51-0.94), with management adherent to the $\mathrm{ABC}$ pathway compared with noncompliance (-Fig. 4). ${ }^{8}$

The integrated care AF pathway approach ("simple as $A B C . . . ")$ has been adopted and promoted in the Primary Care Clinical Pathway for AF Detection and Management (https://bit.ly/2FhrwXQ). The key feedback from multidisciplinary colleagues is the reassurance felt that a holistic approach to management can be streamlined across primary-secondary care, not being regarded as complex but is "simple as ABC..." The ABC pathway is now included within guidelines from American College of Chest Physicians, ${ }^{9}$ the Korean national AF guidelines, ${ }^{10}$ and the 2020 European AF guidelines, ${ }^{11}$ and is therefore recommended in this guideline as part of the holistic approach to AF management. In this APHRS consensus document, we will particularly focus on the " $\mathrm{A}$ " domain and update data for stroke prevention in AF, but would highlight the importance of full compliance with the $A B C$ pathway to improve outcomes in AF patients.

\section{Recommendation}

An integrated care or holistic management approach, based on the $A B C$ pathway is recommended to improve outcome in the Asian AF population:

- "A": Avoid stroke with anticoagulation, i.e., well-managed warfarin (TTR $>65-70 \%$ ) or NOAC.

- "B": Better symptom management with patientcentered symptom-directed decisions for rate or rhythm control.

- "C": Cardiovascular risk and comorbidity management (BP control, heart failure, cardiac ischemia, sleep 


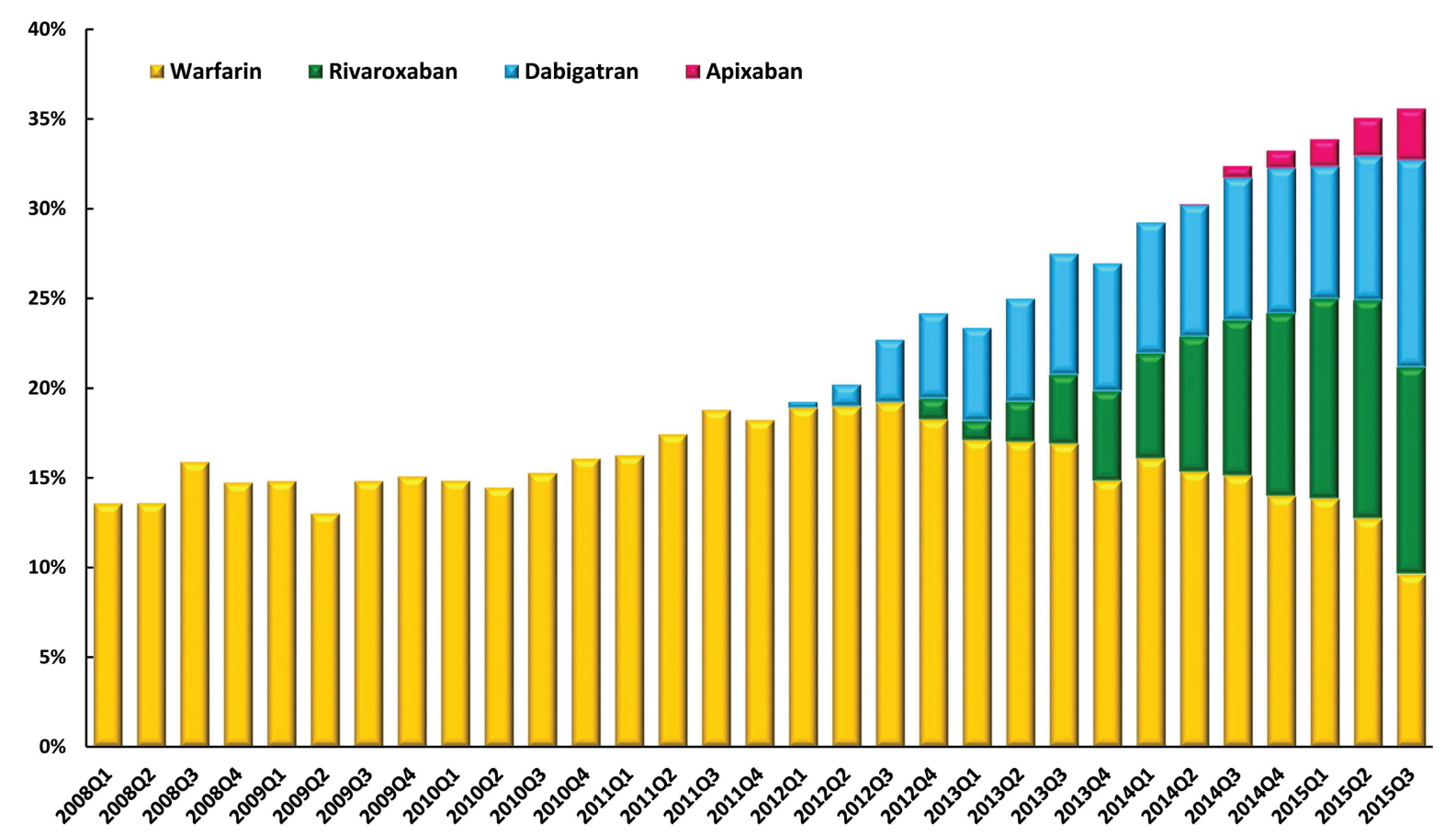

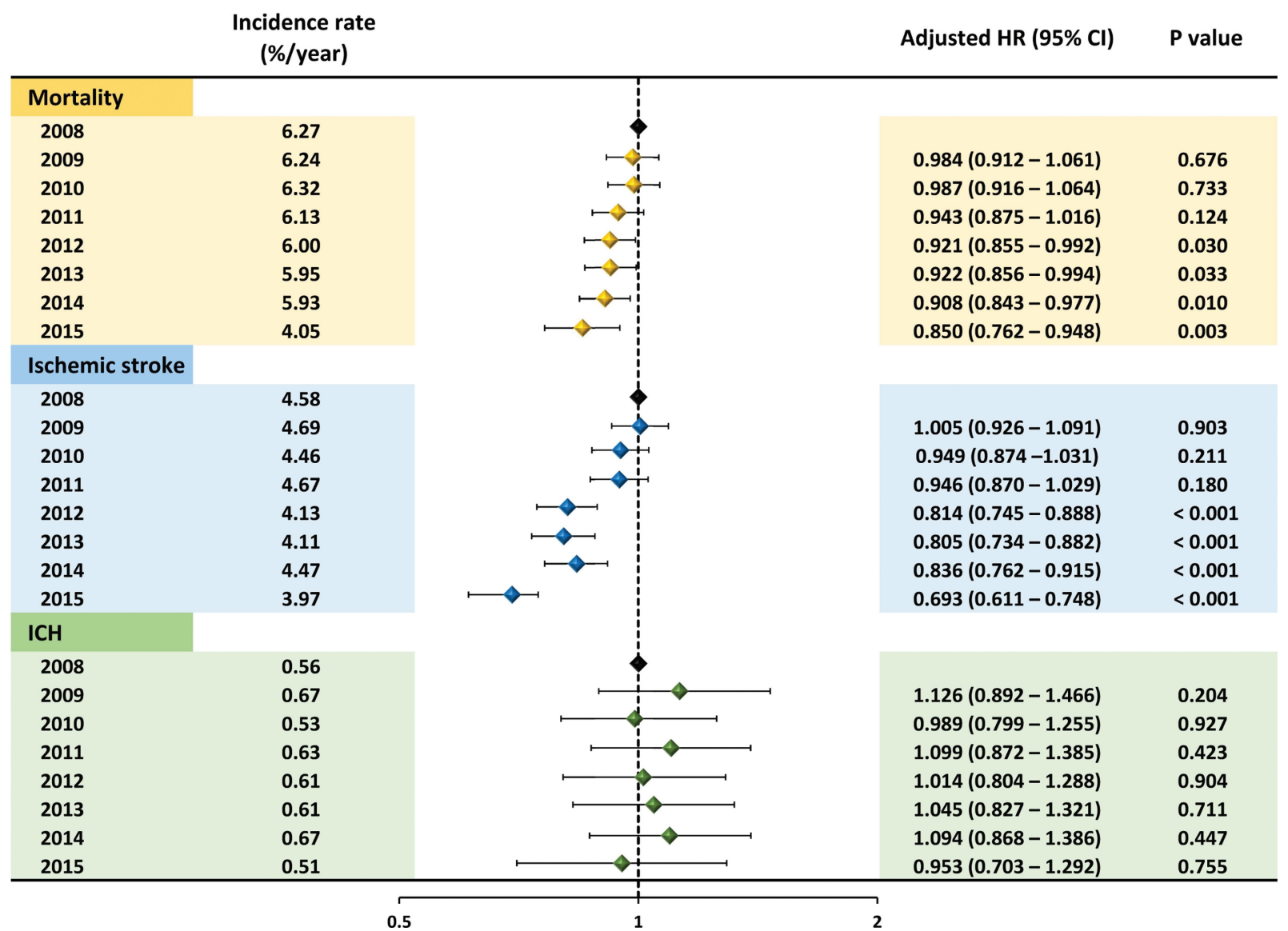

Fig. 2 Temporal trend of prescriptions of OACs and risks of clinical events in newly diagnosed AF patients. The figure was redrawn and data were adapted from Chao et al. ${ }^{5} \mathrm{AF}$, atrial fibrillation; OACs, oral anticoagulants. 


\section{The ABC pathway for integrated care management}

\begin{tabular}{|c|c|c|}
\hline 'A' Avoid stroke & \multirow[b]{2}{*}{ 'Atrial fibrillation 3-step' } & Step 1 \\
\hline $\begin{array}{l}\text { Optimize stroke } \\
\text { prevention }\end{array}$ & & $>$ Identify low risk patients \\
\hline $\begin{array}{l}\text { 'B' Better symptom } \\
\text { management } \\
\text { Treat symptoms }\end{array}$ & $\begin{array}{l}\text { Patient-centered and symptom- } \\
\text { directed decisions on rate or } \\
\text { rhythm control }\end{array}$ & \multirow{2}{*}{$\begin{array}{l}\text { Offer stroke prevention to } \\
\text { patients with one or more risk } \\
\text { factors for stroke } \\
\text { Assess bleeding risk }\end{array}$} \\
\hline $\begin{array}{l}\text { 'C' Cardiovascular } \\
\text { and other } \\
\text { comorbidities } \\
\text { Manage risk factors }\end{array}$ & $\begin{array}{l}\text { Manage hypertension, heart } \\
\text { failure, diabetes mellitus, cardiac } \\
\text { ischemia, and sleep apnea } \\
\text { Lifestyle changes: obesity } \\
\text { reduction, regular exercise, and }\end{array}$ & \\
\hline & $\begin{array}{l}\text { reduction of alcohol and } \\
\text { stimulant use } \\
\text { Patient psychological morbidity } \\
\text { Consider patient values and } \\
\text { preferences }\end{array}$ & $\begin{array}{l}\text { Decide on OACs (either a } \\
\text { NOAC [preferred] or VKA with } \\
\text { well-managed TTR) }\end{array}$ \\
\hline
\end{tabular}

Fig. 3 The $A B C$ pathway of integrated care management. The figure was redrawn and modified from Lip et al. ${ }^{7}$ ABC, Atrial fibrillation Better Care; NOAC, non-vitamin K antagonist oral anticoagulant; OAC, oral anticoagulant; TTR, time in therapeutic range; VKA, vitamin K antagonist.

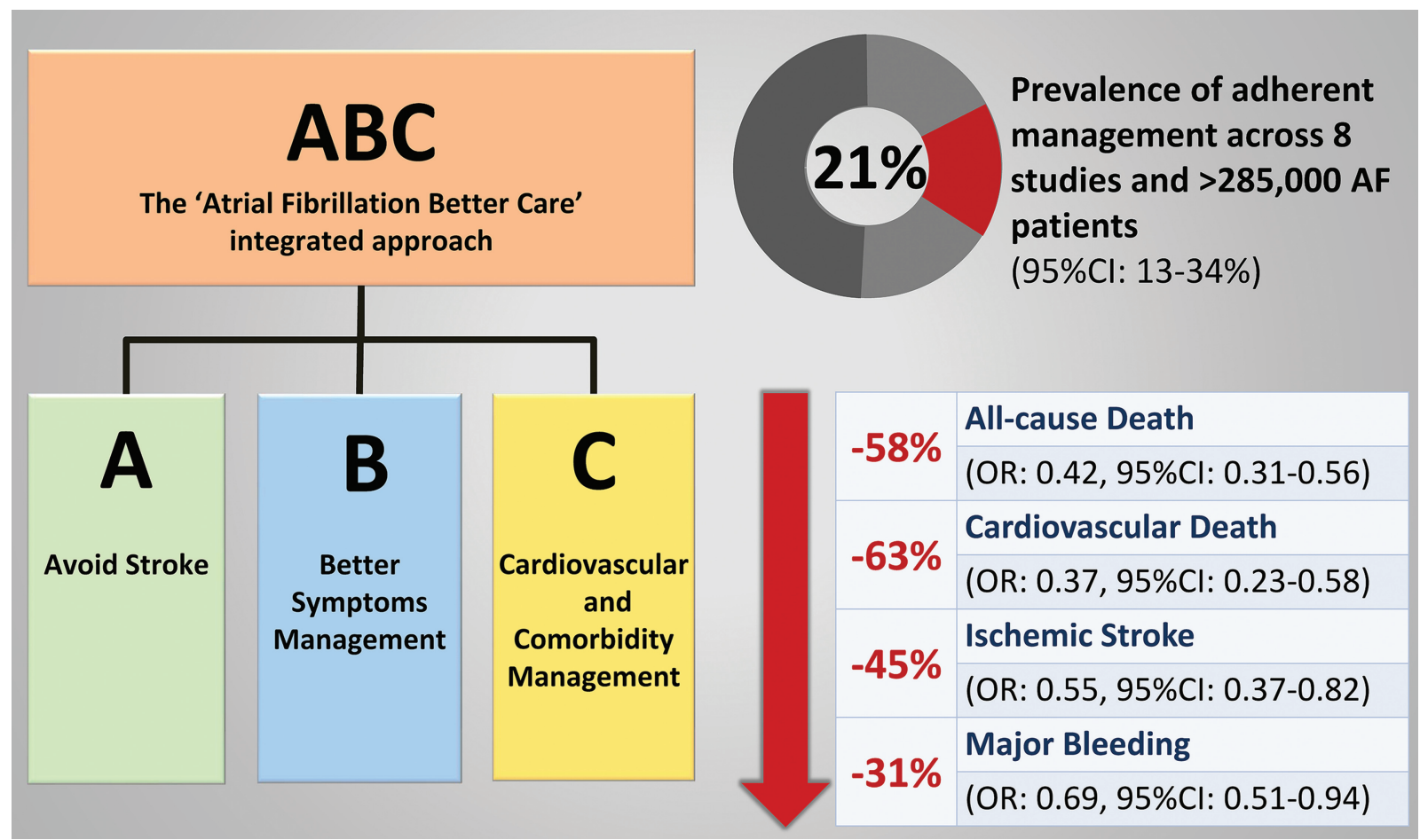

Fig. 4 Impacts of adherence to the ABC pathway on clinical outcomes in AF patients. The figure was redrawn and modified from Romiti et al. ${ }^{8}$ $\mathrm{ABC}$, Atrial fibrillation Better Care; $\mathrm{Cl}$, confidence interval; OR, odds ratio. 


\section{Cumulative incidence (\%) of increment of $\mathrm{CHA}_{2} \mathrm{DS}_{2}$-VASc score to $\geq 1$ for males and $\geq 2$ for females among initially low-risk incident AF patients (score 0 for males and 1 for females)}

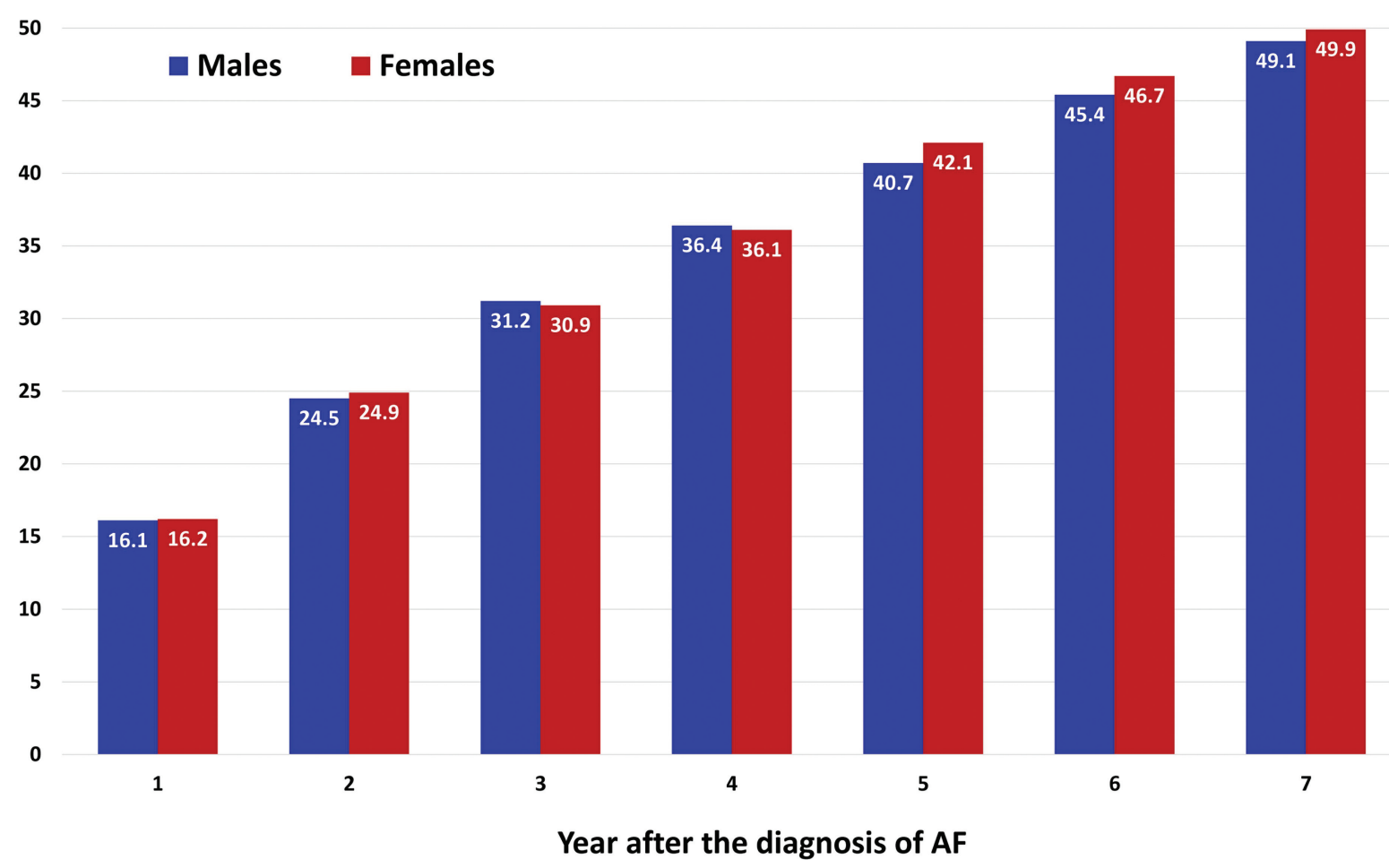

Fig. 5 Cumulative incidences of increment of $\mathrm{CHA}_{2} \mathrm{DS}_{2}$-VASc score to $\geq 1$ (males) or $\geq 2$ (females). The figure was redrawn and data were adapted from Chang et al and Chao et al. ${ }^{23,25} \mathrm{AF}$, atrial fibrillation.

apnea, etc.) as well as lifestyle changes (obesity reduction, regular exercise, reducing alcohol/stimulants, psychological morbidity, etc.).

\section{Stroke Risk Assessment (and Re- assessment)}

In our 2017 consensus document, we recommended the use of the $\mathrm{CHA}_{2} \mathrm{DS}_{2}$-VASc score for stroke risk assessment for Asian AF patients. ${ }^{12}$

In this focused update, we still recommend the use of the $\mathrm{CHA}_{2} \mathrm{DS}_{2}$-VASc score as the stroke risk prediction scheme since it has been well validated in the Asian AF population. ${ }^{13-18}$ We should acknowledge that all clinical risk stratification scores are simplifications to aid decision-making, and to recognize the limitations of such scores. For example, there are many stroke risk factors ${ }^{19}$ and only the more common and validated ones have been included into risk scores, such as the $\mathrm{CHA}_{2} \mathrm{DS}_{2}$-VASc score.

The impact of individual stroke risk factors is not uniform, and for a single $\mathrm{CHA}_{2} \mathrm{DS}_{2}$-VASc risk factor in those aged $<65$, and assuming an ischemic stroke risk treatment threshold of $\geq 1 \%$ per year with NOACs, the tipping point with heart failure as a single risk was age 35 years, while for patients with hypertension, diabetes mellitus, and vascular diseases, the age thresholds for treatment were 50 years, 50 years, and 55 years, respectively. ${ }^{20,21}$ Not all $\mathrm{CHA}_{2} \mathrm{DS}_{2}$-VASc risk factors carry equal weight, as event rates would be dependent on the population studied (e.g., hospitalized vs. community), study type (trial vs. real world), ethnicity, and study methodology. 22

Also, stroke risk is not static, given that aging and incident comorbidities would increase risk and the dynamic nature of stroke risk in AF would result in increments of their $\mathrm{CHA}_{2} \mathrm{DS}_{2}$-VASc scores. ${ }^{23}$ For example, in a study from Taiwan which enrolled 31,039 AF patients without comorbidities of the $\mathrm{CHA}_{2} \mathrm{DS}_{2}$-VASc score except for age and sex at baseline, the mean $\mathrm{CHA}_{2} \mathrm{DS}_{2}$-VASc scores increased from 1.29 to 2.31 during a follow-up of 171,956 person-years (-Fig. 5). ${ }^{23-25}$ Similar observations were reported in the Korean nationwide AF registry. ${ }^{26}$

Both the follow-up $\mathrm{CHA}_{2} \mathrm{DS}_{2}$-VASc score and change in stroke risk ("delta-CHA $\mathrm{DS}_{2}$-VASc" score, i.e., the difference between the baseline and follow-up scores) had better predictive value for ischemic stroke compared with the baseline $\mathrm{CHA}_{2} \mathrm{DS}_{2}$-VASc score. ${ }^{24,27}$ For initially low-risk $\left(\mathrm{CHA}_{2} \mathrm{DS}_{2}\right.$-VASc score 0 for males or 1 for females) nonanticoagulated AF patients, the use of OACs once their $\mathrm{CHA}_{2} \mathrm{DS}_{2}$-VASc scores increased was associated with a lower risk of clinical events. ${ }^{28}$

In summary, regular reassessment of stroke risk of AF patients and the timely prescriptions of OACs once the stroke risk of patients increased is important, given the increase in stroke risks with age and new comorbidities. 


\section{Frequency of Stroke Risk Reassessment}

Data regarding the reasonable timing interval at which the stroke risk of AF patients should be reassessed are limited. In the study by Chao et al, which studied $14,606 \mathrm{AF}$ patients with a baseline $\mathrm{CHA}_{2} \mathrm{DS}_{2}$-VASc score of 0 (males) or 1 (females), 6,188 patients acquired new risk factors with the acquisition of one or more new comorbidities approximately 4 to 5 months after their initial AF diagnosis; the most common incident comorbidity was hypertension, followed by heart failure, diabetes mellitus, and vascular disease; indeed, the onset of new comorbidities would depend on the type of comorbidity. Importantly, 596 of these original patients experienced ischemic stroke and the duration from the acquirement of incident comorbidities to the occurrence of ischemic stroke was an average of 4.4 months for $90 \%$ of the patients. ${ }^{28}$ Based on these data, 4 months may be a reasonable timing interval at which the stroke risk of AF patients should be reassessed.

\section{Recommendations}

- The $\mathrm{CHA}_{2} \mathrm{DS}_{2}$-VASc score is recommended for stroke risk assessment for Asian AF patients.

- The stroke risk of AF patients is not static and should be reassessed regularly (at least annually and every 4 months if possible).

- In patients with AF initially at low risk of stroke $\left(\mathrm{CHA}_{2} \mathrm{DS}_{2}\right.$ $\mathrm{VASc}=0$ in men, or 1 in women), a reassessment of stroke risk should ideally be made at 4 months after the index evaluation and OACs should be prescribed in a timely manner once their $\mathrm{CHA}_{2} \mathrm{DS}_{2}$-VASc scores increase.

\section{Bleeding Risk Assessment and Reassessment}

As with the 2017 consensus document, the HAS-BLED score is recommended for bleeding risk assessment for Asian $\mathrm{AF}$ patients in this focused update. In a PCORI systematic review and evidence appraisal, the HAS-BLED score was found to be the best score for bleeding risk prediction. ${ }^{29}$ In a recent analysis of ESC-EHRA EORP-AF General Long-Term Registry, the HAS-BLED score still performed better than the ORBIT score in the contemporary cohort of AF patients treated with NOACs. ${ }^{30}$

The HAS-BLED score has been well validated in Asian cohorts, outperforming other bleeding risk scores (e.g., ATRIA, ORBIT, HEMORRH2AGES) and an approach simply focused only on modifiable bleeding risks. ${ }^{31}$ The HAS-BLED score performs well even in contemporary AF patients taking NOACs. ${ }^{30}$ Bleeding risk is also not static and may change among AF patients initially having a low HAS-BLED score $(\leq 2) .{ }^{32}$ In a previous study from Taiwan, the accuracy of the follow-up or delta HAS-BLED score in the prediction of major bleeding was significantly higher than that of the baseline HAS-BLED score; importantly, the bleeding risk is higher within several months after the increment of the HAS-BLED score. ${ }^{32}$ The HAS-BLED score has also been validated in AF patients who are taking no antithrombotic therapy (e.g., when first diagnosed), antiplatelet therapy (e.g., when AF develops in patients on aspirin for vascular disease), and on anticoagulation (whether warfarin or NOACs). Thus, the HAS-BLED score would be applicable at all steps of the patient-management pathway.

Appropriate use of the HAS-BLED score has been tested in the mAFA-II trial, ${ }^{33}$ which was a prospective cluster-randomized trial that compared an mHealth integrated care approach against usual care. The intervention arm used the HAS-BLED to identify and mitigate modifiable bleeding risks, and schedule high bleeding risk patients for regular review and follow-up; this led to lower major bleeding rates at 1 year and an increase in OAC use. ${ }^{34}$ In contrast, the usual care arm has higher major bleeding and a decline in OAC use (-Fig. 6).

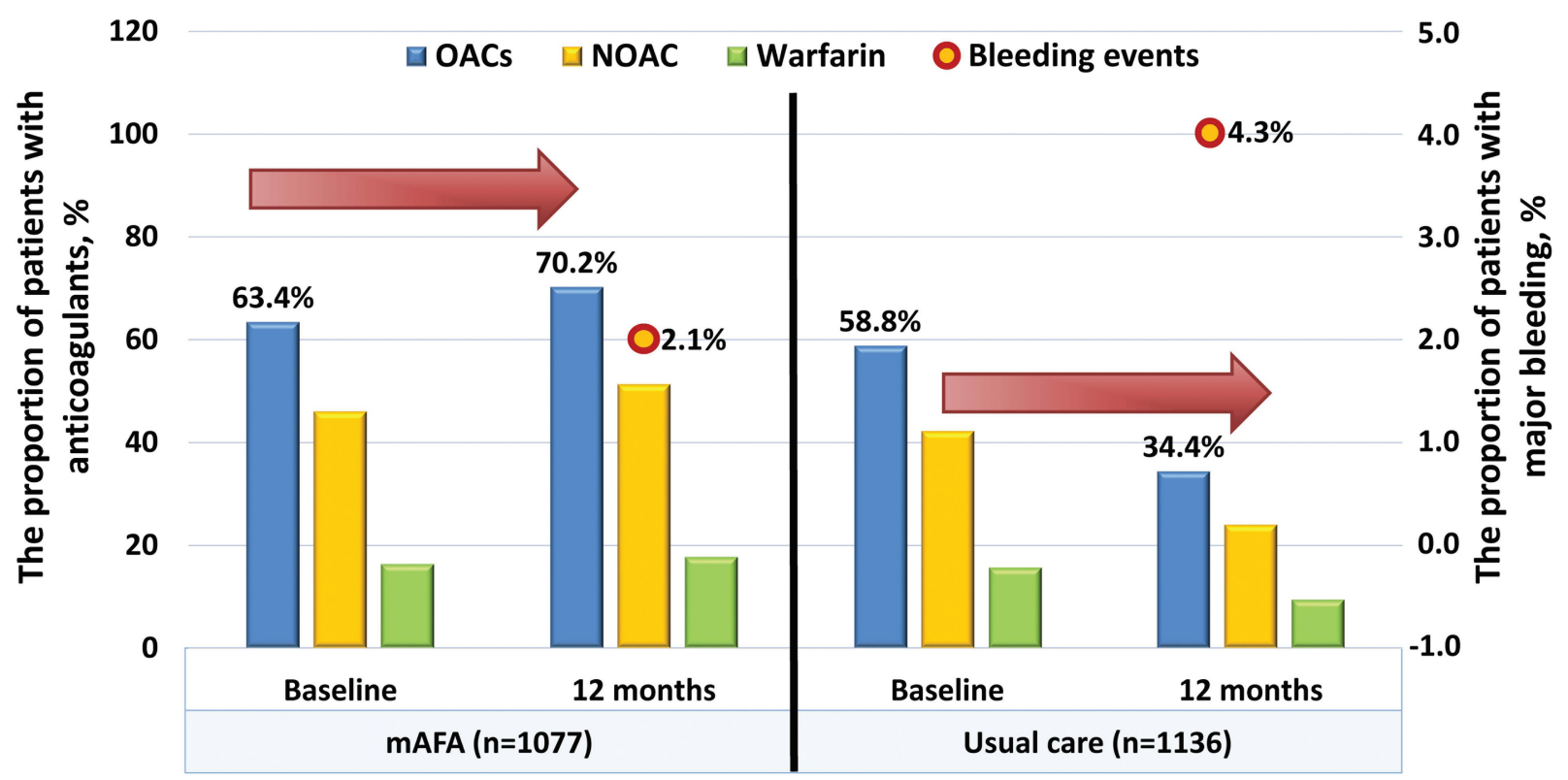

Fig. 6 Use of OACs and risk of bleeding among patients who received integrated care approach and usual care. The figure was redrawn and modified from Guo et al. ${ }^{34} \mathrm{AF}$, atrial fibrillation; NOAC, non-vitamin K antagonist oral anticoagulant; OACs, oral anticoagulants. 


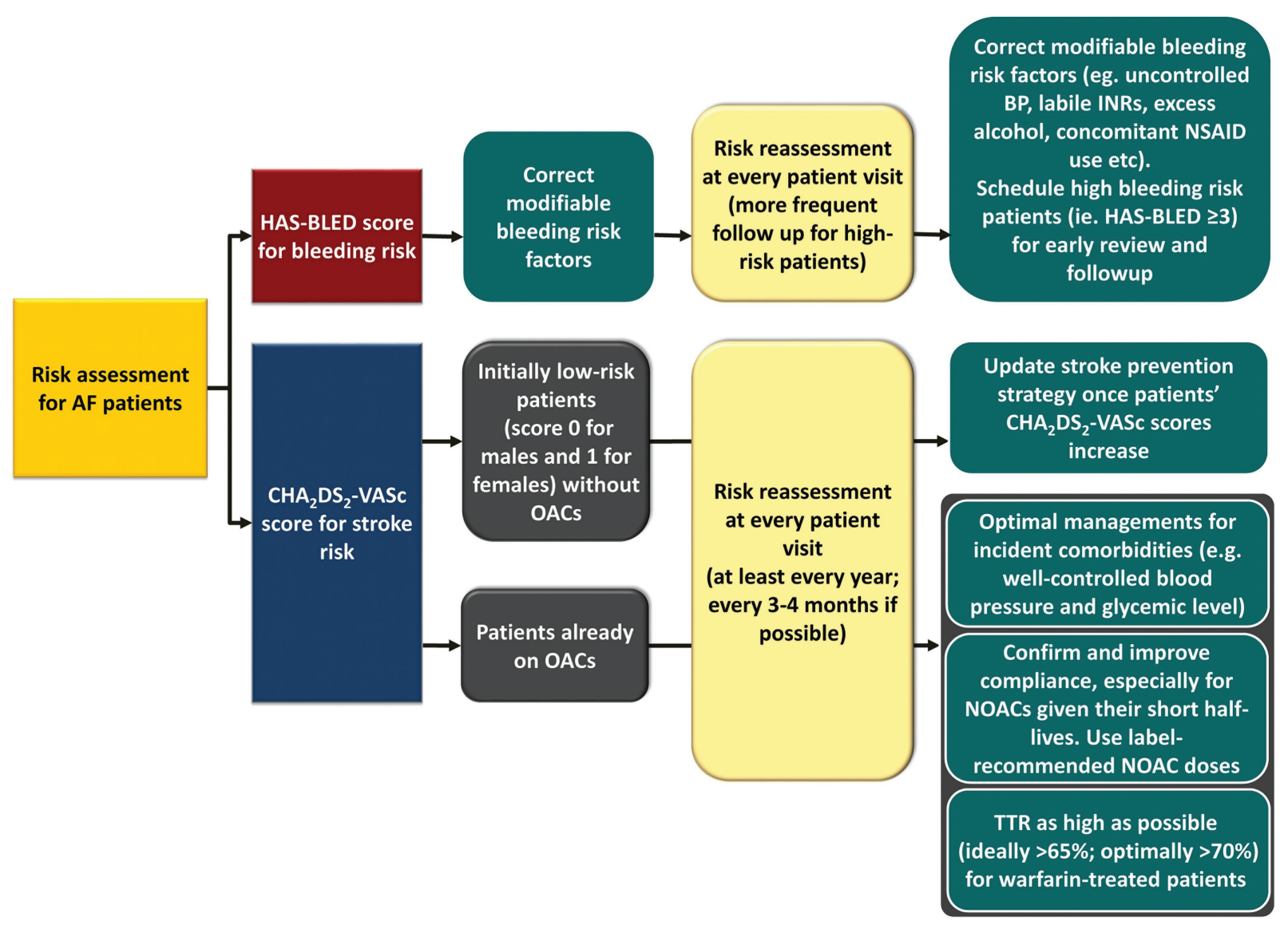

Fig. 7 Stroke and bleeding risk assessment in AF. The figure was redrawn and modified from Chang et al. ${ }^{23}$ AF, atrial fibrillation; BP, blood pressure; INR, international normalized ratio; NOAC, non-vitamin K antagonist oral anticoagulant; NSAIDs, nonsteroidal anti-inflammatory drugs; OACs, oral anticoagulants; TTR, time in therapeutic range.

A recent study from Taiwan further demonstrated that for anticoagulated AF patients with a baseline HAS-BLED score of 0 to 2 which increased to $\geq 3$, the continuation of OACs was associated with better clinical outcomes. ${ }^{35} \mathrm{~A}$ high HAS-BLED score is not a reason to withhold OACs even among AF patients with one non-sex risk factor $\left(\mathrm{CHA}_{2} \mathrm{DS}_{2}\right.$-VASc score 1 for males and 2 for females) but a high bleeding risk (HASBLED score $\geq 3$ ) as the use of OACs was still associated with a lower risk of composite adverse events of ischemic stroke, intracranial hemorrhage (ICH), or mortality (adjusted hazard ratio [aHR]: 0.781 ) in this population. ${ }^{36}$

In summary, bleeding risk reassessment is important for anticoagulated AF patients, and the appropriate and responsible use of bleeding risk scores such as the HAS-BLED score is to identify and mitigate modifiable bleeding risk factors, and to identify high bleeding risk patients for early review and follow-up.

\section{Recommendations}

- For bleeding risk assessment, a formal structured riskscore-based bleeding risk assessment with the HAS-BLED score is recommended to help identify nonmodifiable and address modifiable bleeding risk factors, and to identify patients potentially at high bleeding risk for early and more frequent clinical review and follow-up.
- The bleeding risk of AF patients is not static, which should be reassessed regularly, and the identified modifiable bleeding risk factors should be corrected.

- An increased HAS-BLED score in anticoagulated AF patients should not be the only reason to withhold OACs, but reminds physicians to correct modifiable bleeding risk factors and follow up patients more closely.

In this focused update, we emphasize the dynamic natures of $\mathrm{CHA}_{2} \mathrm{DS}_{2}$-VASc and HAS-BLED scores and highly emphasize the clinical importance of risk reassessment. The recommended clinical practice about stroke and bleeding risk assessments is summarized in - Fig. $\mathbf{7}$.

\section{Approach to Stroke Prevention in Asian AF Patients}

Given the limitations of all stroke risk scores in predicting high stroke risk in AF patients and the dynamic nature of stroke risk, the artificial categorization into low, moderate, and high risk strata is discouraged. Thus, stroke prevention (which is oral anticoagulation) should be the default strategy, unless patients are at low risk (defined as $\mathrm{CHA}_{2} \mathrm{DS}_{2}$ VASc score 0 in males or 1 in females). - Fig. 8 shows our recommendations, which were consistent to other guidelines. ${ }^{9}$

Patients with AF and significant valvular heart disease (previously referred to as "valvular AF"), defined as 


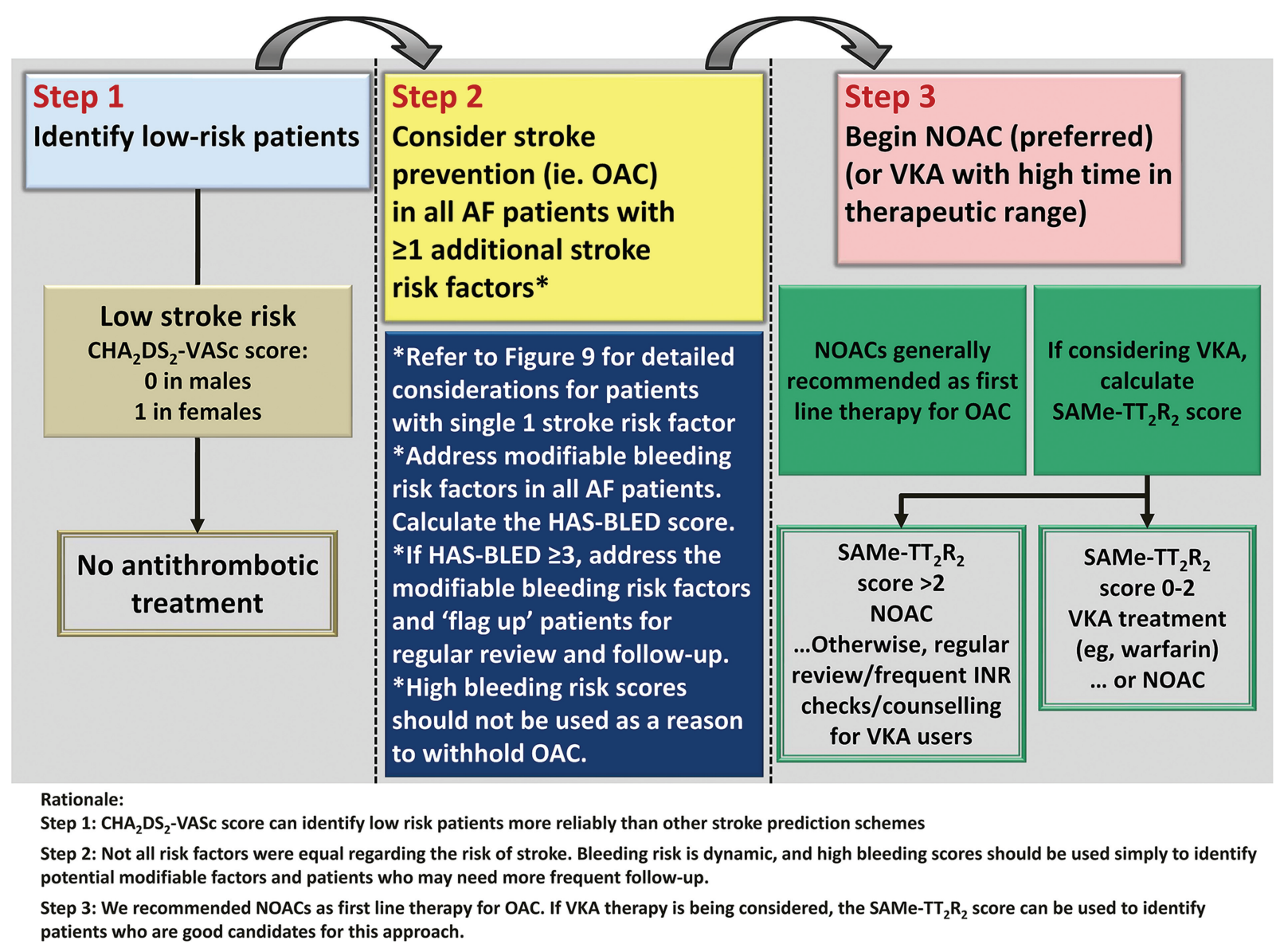

Fig. 8 Three-step approach for the use of OACs for stroke prevention in AF. The flowchart was redrawn and modified from Lip et al. ${ }^{9}$ AF, atrial fibrillation; INR, international normalized ratio; NOAC, non-vitamin K antagonist oral anticoagulant; OACs, oral anticoagulants; VKA, vitamin K antagonist.

prosthetic mechanical heart valves or moderate-severe mitral stenosis, should be offered warfarin, when oral anticoagulation is recommended. ${ }^{37}$ Indeed, NOACs are contraindicated in such patients.

In other patients without significant valvular heart disease (so-called "nonvalvular AF" [NVAF]), the first step (Step $1)$ is to identify low-risk patients $\left(\mathrm{CHA}_{2} \mathrm{DS}_{2} \mathrm{VASc}\right.$ score 0 in males or 1 in females) where no antithrombotic therapy is recommended. The next step (Step 2) is to offer stroke prevention (i.e., oral anticoagulation) to patients with $\geq 1$ non-sex stroke risk factors (i.e., $\mathrm{CHA}_{2} \mathrm{DS}_{2} \mathrm{VASc}$ score $\geq 1$ in males or $\geq 2$ in females). Most of the randomized trials included patients with $\geq 2$ non-sex stroke risk factors, but some clinical trials with warfarin (ACTIVE-W), dabigatran, and apixaban (RE-LY, ARISTOTLE, AVERROES) included patients with a single non-sex stroke risk factor. ${ }^{38-41}$

Since the risk of stroke of each $\mathrm{CHA}_{2} \mathrm{DS}_{2}$-VASc risk component was not the same and age is an important driver, patients' ages and the comorbidities which contribute to the score 1 for males or 2 for females could be considered when making management decisions about the use of OACs or not ${ }^{20,42-46}$ as summarized in - Fig. 9. As OAC is being started, bleeding risk assessment is recommended, using the HASBLED score to identify and mitigate modifiable bleeding risks, and to identify high bleeding risk patients for early review and follow-up.

Step 3 is to make the choice of OAC. We recommend the use of NOACs in preference to warfarin for stroke prevention. If NOACs are used, the recommended label dosing is important, given that the best outcomes are with label-adherent prescribing. ${ }^{47-52}$ Apart from guideline-directed anticoagulation prescribing, adherence and persistence with therapy are important. ${ }^{53-55}$

If warfarin is considered, we recommend a target international normalized ratio (INR) of 2.0 to 3.0 with an average TTR $\geq 65 \%$ (ideally $\geq 70 \%$ ). We do not recommend low-intensity anticoagulation or lower target INRs, given the higher risk of thromboembolism although bleeding risk is lower. ${ }^{56}$ Of note, a "one off" INR reading gives no indication of the quality of anticoagulation control, and many serious bleeds occur when the INR is between 2.0 and $3.0 .^{57} \mathrm{~A}$ high TTR is associated with low rates of stroke and bleeding, ${ }^{58}$ but many factors influence the quality of anticoagulation control. The more common and validated factors associated with poor labile INRs have been used to formulate clinical risk scores such as the SAMe-TT ${ }_{2} R_{2}$ scores. A high SAMe-TT ${ }_{2} R_{2}$ score $(>2)$ is associated with a likelihood of poor TTR, and such patients should be flagged up for more attention to ensure good-quality anticoagulation 


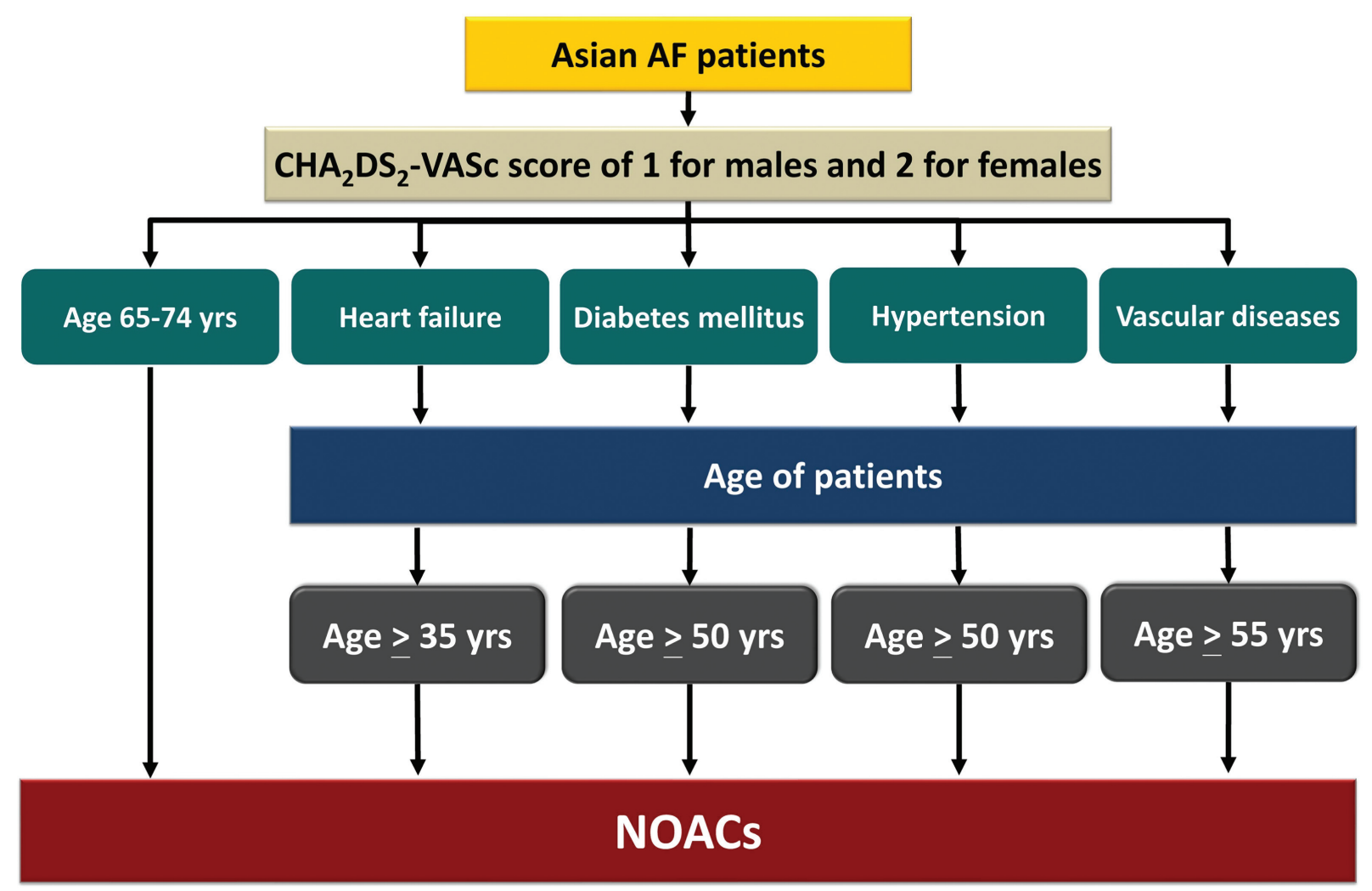

Fig. 9 Considerations about the use of NOACs for Asian AF patients with a $\mathrm{CHA}_{2} \mathrm{DS}_{2}$-VASc score of 1 (males) or 2 (females). AF, atrial fibrillation; NOAC, non-vitamin $\mathrm{K}$ antagonist oral anticoagulant.

(e.g., education and counseling, more frequent INR checks) or to reconsider the decision to prescribe NOACs (if suitable). ${ }^{59-63}$ One ongoing prospective randomized trial, TREAT-AF, is examining the impact of an educational intervention versus usual care on anticoagulation therapy control based on a SAMe- $\mathrm{TT}_{2} \mathrm{R}_{2}$ score-guided management strategy amongst anticoagulant-naïve Thai patients with $\mathrm{AF}^{64}$

\section{Recommendations}

- In AF patients with mechanical heart valves or moderateto-severe mitral stenosis, warfarin is recommended.

- ForstrokepreventioninAFpatientswithoutsignificantvalvular heart disease (i.e., mechanical heart valves or moderate-tosevere mitral stenosis; so-called "valvular AF") who are eligible for OAC, NOACs are recommended in preference to VKAs.

- Clinical pattern of AF (i.e., whether first detected, paroxysmal, persistent, long-standing persistent, permanent) should not condition the indication to thromboprophylaxis, if stroke risk factors are present.

- For stroke risk assessment, a risk-factor-based approach is recommended, using the $\mathrm{CHA}_{2} \mathrm{DS}_{2}$-VASc stroke risk score to initially identify patients at "low stroke risk" $\left(\mathrm{CHA}_{2} \mathrm{DS}_{2}-\right.$ $\mathrm{VASc}=0$ in men, or 1 in women) who should not be offered antithrombotic therapy.

- In AF patients with $\mathrm{CHA}_{2} \mathrm{DS}_{2}$-VASc score $\geq 2$ in men or $\geq 3$ in women, OAC is recommended for stroke prevention.
- In AF patients with a $\mathrm{CHA}_{2} \mathrm{DS}_{2}$-VASc score of 1 in men or 2 in women, OAC should be considered for stroke prevention. Different age thresholds for different comorbidities may help guide NOAC use (e.g., age 35 years for heart failure, 50 years for hypertension or diabetes mellitus, and 55 for vascular diseases).

- If a VKA is used, a target INR of 2.0 to 3.0 is recommended, with individual TTR $\geq 65 \%$ (ideally $\geq 70 \%$ ).

- A high SAMe-TT ${ }_{2} R_{2}$ score $(>2)$ is associated with a likelihood of poor TTR, and such patients have more attention to ensure good-quality anticoagulation (e.g., education and counseling, more frequent INR checks) or to reconsider the decision to prescribe NOACs (if suitable).

- In patients on VKAs with low time in INR therapeutic range (e.g., TTR $<70 \%$ ), recommended options are:

- Switching to a NOAC but ensuring good adherence and persistence with therapy.

- Efforts to improve TTR (e.g., education/counseling and more frequent INR checks).

- Antiplatelet therapy alone (monotherapy or aspirin in combination with clopidogrel) is not recommended for stroke prevention in AF patients.

- Estimated bleeding risk, in the absence of absolute contraindications to $\mathrm{OAC}$, or patients at high risk of falls, should not in itself guide treatment decisions to use OAC for stroke prevention. 


\section{Review Update Data Regarding Warfarin (Including INR Range) in Asia}

When OAC is being considered, NOACs are the preferred option for stroke prevention in AF, because the benefits of NOAC on efficacy and safety compared with the VKAs are more profound in Asian than non-Asian population. ${ }^{65}$ In some settings, the use of VKA is still needed because of the high cost of NOACs or in patients with specific indications including moderate to severe mitral stenosis and mechanical heart valves. Maintenance of a high TTR has been shown to reduce the risk of ischemic and bleeding events and should be the primary goal in the treatment of these patients independent of the type of management approach. Conversely, a change in the approach to these patients needs to be considered if a low TTR is consistently observed.

Several observational studies suggested that low-intensity warfarin therapy can reduce hemorrhage without increasing thromboembolism for East-Asian patients with NVAF receiving warfarin therapy, but the evidence is weak and no focus on quality of anticoagulation control, as reflected by TTR. ${ }^{66,67}$ In a systematic review and evidence appraisal, lowintensity anticoagulation or lower target INRs are associated with a higher risk of thromboembolism although bleeding risk may be lower..$^{56}$ Of note, a "one off" INR reading does not reflect the quality of anticoagulation control, especially since many serious bleeds actually occur when the INR is between 2.0 and 3.0. ${ }^{57}$ Hence, we strongly recommend evidencebased management, with the strongest data currently for INR 2.0 to 3.0 and TTR ideally $\geq 65 \%$ (or even $70 \%$ ) in Asian patients. ${ }^{68}$ We should ensure TTR is $\geq 65 \%$ (optimal $\geq 70 \%$ ), with appropriate education and counseling, or more frequent INR checks. Efforts to improve OAC uptake, adherence, and persistence with therapy are also crucial, as are efforts to improve service provisions. ${ }^{69-71}$

\section{Recommendations}

- The use of VKA is recommended in patients with moderate to severe mitral stenosis and mechanical heart valve.

- For the optimal management of VKA therapy, INR of 2.0 to 3.0 is recommended in Asian AF patients, with attention to ensure TTR is $\geq 65 \%$.

Updates of the subanalyses of trials in Asia:

The results of the four pivotal phase III NOAC trials showed that all NOACs were at least noninferior to warfarin in prevention of stroke/thromboembolism, and NOACs were associated with lower rates of intracranial bleeding than was warfarin. In the meta-analysis of four NOACs, ${ }^{72}$ NOACs significantly reduced stroke or systemic embolic events by $19 \%$ compared with warfarin (relative risk [RR]: $0.81,95 \% \mathrm{CI}$ : $0.73-0.91 ; p<0.0001$ ), mainly driven by a reduction in hemorrhagic stroke (RR: $0.49, \quad 95 \%$ Cl: 0.38-0.64; $p<0.0001)$. NOACs also significantly reduced all-cause mortality (RR: $0.90,95 \%$ CI: $0.85-0.95 ; p=0.0003$ ) and ICH (RR: $0.48,95 \%$ CI: $0.39-0.59 ; p<0.0001$ ), but increased gastrointestinal (GI) bleeding (RR: $1.25,95 \% \mathrm{CI}: 1.01-1.55 ; p=0.04$ ).
There was a greater RR reduction in major bleeding with NOACs when the TTR was less than $66 \%$ than when it was $66 \%$ or more (RR: $0.69,95 \%$ CI: $0.59-0.81$ vs. RR: $0.93,95 \% \mathrm{CI}$ : $0.76-1.13 ; p$ for interaction $=0.022$ ).

The efficacy and safety of NOACs was more profound in the Asian population than in non-Asian population. ${ }^{65} \mathrm{Com}$ paring with VKAs, standard-dose NOACs reduced stroke or systemic embolism (SE; OR $=0.65$ vs. $0.85, p$ interaction $=0.045$ ) more in Asians than in non-Asians and were safer in Asians than in non-Asians for major bleeding ( $O R=0.57$ vs. $0.89, p$ interaction $=0.004)$ and hemorrhagic stroke $(\mathrm{OR}$ $=0.32$ vs. $0.56, p$ interaction $=0.046$ ). There was no excess of GI bleeds in Asians, whereas GI bleeding was significantly increased in non-Asians ( $\mathrm{OR}=0.79$ vs. $1.44, p$ interaction $=0.041)$. Generally, reduced-dose NOACs were safer than VKAs without heterogeneity in efficacy and safety between Asians and non-Asians, except for ischemic stroke, major bleeding, and GI bleeding. ${ }^{65}$ In the recent subanalysis of ENGAGE AF-TIMI 48 trial comparing patients of Asian and non-Asian races, Asians treated with warfarin had a higher adjusted risk of ICH (aHR: 1.71, $p=0.03$ ) compared with nonAsians. ${ }^{73}$ Compared with warfarin, higher dose edoxaban significantly reduced ICH while preserving the efficacy of stroke prevention in both Asians and non-Asians. Two of three net clinical outcomes appeared to be more favorably reduced with edoxaban in Asians compared with non-Asians $\left(p_{\text {int }}=0.063\right.$ for primary, 0.037 for secondary, and 0.032 for third net clinical outcomes, respectively).

\section{Real-World Data about NOACs in Asia}

In a systematic review and meta-analysis of real-world comparisons of NOACs for stroke prevention in Asian patients with $\mathrm{AF}^{74}$ the NOACs were associated with lower risks of thromboembolism (HR: 0.70; [95\% CI: 0.63-0.78]), acute myocardial infarction (0.67; [0.57-0.79]), all-cause mortality $(0.62$; $[0.56-0.69])$, major bleeding $(0.59$; [0.50$0.69])$, ICH (0.50; [0.40-0.62]), GI bleeding (0.66; [0.46$0.95])$, and any bleeding $(0.82$; [0.73-0.92]) than warfarin. While real-world data are no substitute for randomized trials, this meta-analysis shows that the NOACs had greater effectiveness and safety compared with warfarin in realworld practice for stroke prevention, among Asian patients with NVAF. ${ }^{74}$

NOACs also showed better effectiveness and safety than warfarin in "high risk" real-world Asian AF populations including the very elderly, those with low body weight or liver disease. ${ }^{45,75-80}$

\section{The Importance of On-Label Dosing of NOACs in Asians}

Varying degrees of renal function require recommendations for reduced dosing regimens of NOACs; however, different cut-off values for age, body weight, or interacting drugs also require consideration for appropriate dose selection. In routine clinical practice in Asia, prescribed NOAC doses are often inconsistent with drug labeling. ${ }^{47-50,52}$ These 
prescribing patterns may be associated with worse safety profiles with no benefit in effectiveness in patients with severe kidney disease and worse effectiveness with no benefit in safety in apixaban-treated patients with normal or mildly impaired renal function. ${ }^{81,82}$

In meta-analysis of four NOAC trials, low-dose NOAC regimens showed similar overall reductions in stroke or systemic embolic events to warfarin (RR: $1.03,95 \% \mathrm{CI}$ : $0.84-1.27 ; p=0.74$ ), and a more favorable bleeding profile (RR: $0.65,95 \%$ CI: $0.43-1.00 ; p=0.05$ ), but significantly more ischemic strokes (RR: $1.28,95 \% \mathrm{CI}: 1.02-1.60 ; p=0.045){ }^{72}$

In patients eligible for reduced-dose NOACs, effects of reduced-dose NOACs compared with warfarin on stroke or SE (RR 0.84, 95\% Cl 0.69-1.03) and on major bleeding (RR: 0.70, 95\% CI: 0.50-0.97) were consistent with those of full-dose NOACs relative to warfarin (RR: $0.86,95 \% \mathrm{CI}: 0.77-0.96$ for stroke or SE and RR: $0.87,95 \% \mathrm{CI}: 0.70-1.08$ for major bleeding; interaction $p$-values of 0.89 and 0.26 , respectively). In addition, NOACs were associated with reduced risks of hemorrhagic stroke, ICH, fatal bleeding, and death regardless of patients' eligibilities for NOAC dose reduction (interaction $p>0.05$ for each). ${ }^{83}$

When checking the eligibility and determining the dosages of NOACs, it should be emphasized that the creatinine clearance $(\mathrm{CCr})$ of AF patients should be calculated using the Cockcroft-Gault (CG) equation which was adopted in four pivotal randomized clinical trials. ${ }^{84}$ Compared with the CG formula, modified diet in renal disease (MDRD) or Chronic Kidney Disease Epidemiology Collaboration (CKD-EPI) equations would overestimate the renal functions of AF patients, especially for the elderly ( $\geq 75$ years) and those with a low body weight $(<50 \mathrm{~kg}) .^{85}$ The overestimations of the estimated glomerular filtration rates (eGFRs) would potentially result in inappropriate dosing of NOACs (mainly overdoing), and may therefore, attenuate the advantages of NOACs compared with warfarin. ${ }^{85}$

A dose reduction of rivaroxaban in Asian patients might be necessary, but lacks the confirmation in large adequately powered prospective randomized clinical trials. Pharmacokinetic modeling data indicated that, at steady state, the distribution of both the maximum concentration and area under the curve (AUC) of rivaroxaban in Japanese patients with $\mathrm{AF}$ who received a $15 \mathrm{mg}$ o.d. (once daily) dose of rivaroxaban would be comparable to the $C_{\max }$ and AUC 0 to 24 , in Caucasian patients with AF who received a $20 \mathrm{mg}$ o. d. dose. Accordingly, instead of the 20 and $15 \mathrm{mg}$ o.d. dose, the 15 and $10 \mathrm{mg}$ o.d. doses of rivaroxaban were selected in Japan. The Korean AF guidelines recommend the use of $15 \mathrm{mg}$ o.d. dose of rivaroxaban in very elderly ( $\geq 80$ years) AF patients. ${ }^{10}$ Another recent study from Taiwan which compared the clinical outcomes of AF patients receiving rivaroxaban following ROCKET-AF and J-ROCKET AF dosing regimens demonstrated that the risks of stroke/systemic and major bleeding did not differ significantly between the two groups. ${ }^{86}$ However, a lower risk of major bleeding was observed for J-ROCKET AF dosing among patients with an eGFR $<50 \mathrm{~mL} / \mathrm{min}$ with a borderline $p$-value of $0.0445 .{ }^{86}$ Of note, off-label underdosing rivaroxaban $(10 \mathrm{mg} / \mathrm{d}$ for patients with an eGFR $>50 \mathrm{~mL} / \mathrm{min}$ ) should be avoided since it was associated with a 2.75-fold higher risk of ischemic stroke. $^{49}$

\section{Recommendations}

- Because NOACs are more effective and safer than warfarin in Asian AF patients, NOACs are the recommended choice of oral anticoagulation in Asian AF patients.

- The CG equation should be adopted to calculate $\mathrm{CCr}$ to determine the dosing of NOACs.

- On-label or guideline-adherent dosing of NOACs is recommended in Asian patients.

\section{AF Complicating Acute Coronary Syndrome/Percutaneous Coronary Intervention}

AF often occurs in patients with coronary artery disease (CAD). It has been reported that 5 to $8 \%$ of patients who undergo percutaneous coronary intervention (PCI) have $\mathrm{AF}^{87,88}$ Importantly, patients with CAD and AF are at high risk of stroke.

In the warfarin era, a major concern in Asian patients with AF was the risk of serious bleeding by combining OAC with antiplatelets; however, temporal trends of patients with $\mathrm{AF}$ undergoing PCI after introduction of NOAC show increasing use of OAC and combination therapy with antiplatelets, especially in the NOAC era (-Fig. 10). ${ }^{89}$

Patients with CAD and AF are not only at risk of stroke, but also at risk of bleeding due to associated comorbidities, and decision making should balance ischemic and bleeding risks when considering the duration, type, and treatment regime especially given the potential sensitivity of Asians to bleeding risks on OAC ( - Fig. 11). ${ }^{90,91}$

In the warfarin era, the WOEST study demonstrated a higher bleeding risk of triple therapy compared with double therapy of OACs and clopidogrel. ${ }^{92}$ More recently, the safety and efficacy of NOACs in combination with antiplatelet drugs in patients with CAD and AF have been reported in the PIONEER AF-PCI, ${ }^{93}$ RE-DUAL PCI, ${ }^{94}$ AUGUSTUS, ${ }^{95}$ and ENTRUST-AF PCI trials. ${ }^{96}$ The summary of those trials is presented in - Table 1.

In the PIONEER AF-PCI, RE-DUAL PCI, and ENTRUST-AF PCI trials, dual therapy with a NOAC and a P2Y12 inhibitor was compared with a triple therapy with warfarin plus a dual antiplatelet therapy (DAPT). In the RE-DUAL PCI trial, elderly patients ( $\geq 80$ years; age $\geq 70$ years in Japan) were given $110 \mathrm{mg}$ of dabigatran when assigned to the dual therapy group. The PIONEER AF-PCI and RE-DUAL PCI trials demonstrated that dual therapy decreased bleeding and did not increase thrombotic events, as compared with triple therapy. In the ENTRUST-AF PCI trial, dual therapy was noninferior to triple therapy for bleeding. The RE-DUAL PCI trial was also adequately powered to investigate a comparison of the combined dabigatran arms against warfarin for the composite thrombotic outcomes, and no significant difference was seen. The highest ticagrelor use was in RE-DUAL PCI, where $12 \%$ of the trial cohort used ticagrelor instead of clopidogrel; 


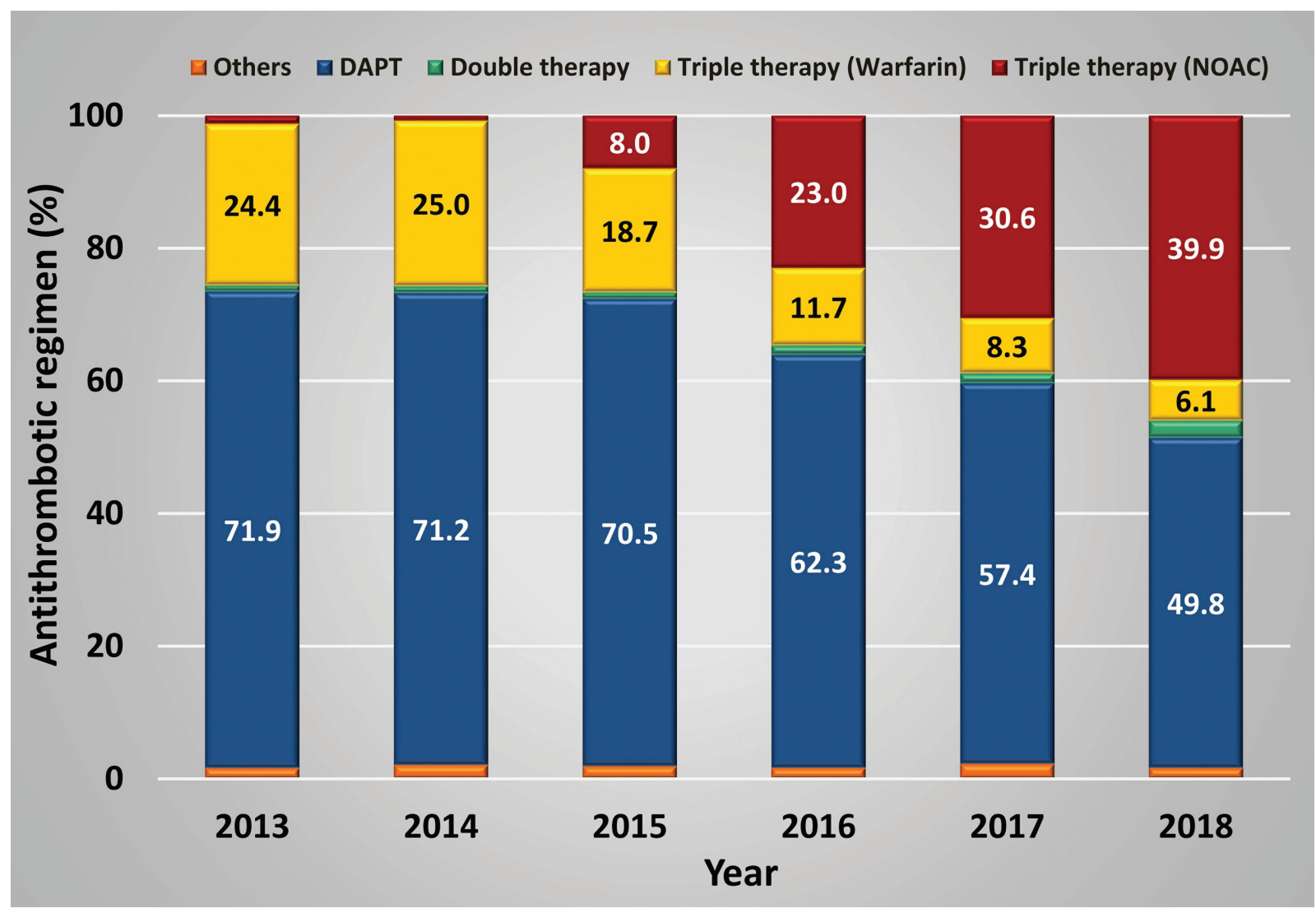

Fig. 10 Increasing use of OACs (especially NOACs) and combination therapy with antiplatelet agents among AF patients undergoing percutaneous coronary intervention. The figure was redrawn and data were adapted from Kwon et al. ${ }^{89}$ AF, atrial fibrillation; DAPT, dual antiplatelet therapy; NOAC, non-vitamin K antagonist oral anticoagulant.

no significant interaction was evident. ${ }^{97}$ Based on these trials, a NOAC-based anticoagulation strategy was safer than a warfarin-based strategy in terms of bleeding.

The role of aspirin was tested in the AUGUSTUS trial using a two-by-two factorial design. ${ }^{95}$ In the AUGUSTUS trial, the use of apixaban reduced bleeding by $31 \%$ as compared with VKAs, and the use of aspirin resulted in an increase in bleeding by $47 \%$, i.e., dual therapy with apixaban and a P2Y12 inhibitor was associated with a lower rate of bleeding than triple therapy or dual therapy with warfarin. Furthermore, patients taking apixaban had a lower incidence of death or hospitalization than those taking VKAs, mainly driven by a reduction in the incidence of hospitalizations. The incidence of death or ischemic events did not differ significantly between aspirin and a placebo or between apixaban and VKAs, but was numerically greater in the placebo-treated patients compared with aspirin. The incidence of stroke decreased by $50 \%$ in patients with apixaban as compared those with VKAs.

In all four trials, randomization was performed after the $\mathrm{PCI}$, and all patients were treated by triple therapy during the periprocedural period, in which stent thromboses were most likely to occur. Thus, this consensus recommends an initial period of triple therapy with OAC plus a DAPT during the $\mathrm{PCI}$ and the following 7 to 28 days, depending on the balance between thrombotic and bleeding risks ( - Fig. 12), as recommended by 2021 European Heart Rhythm Association
(EHRA) Practical Guide on the Use of NOACs in Patients with $\mathrm{AF}^{98}$ Indeed, in patients at very high bleeding risks and acceptable thrombotic risk, aspirin may be dropped much earlier. In contrast, where patients have a high thrombotic risk (e.g., post-acute coronary syndrome [post-ACS]) but acceptable bleeding risks, the period of triple therapy should be continued for at least 4 weeks.

Following the period of triple therapy, patients should be managed with an OAC plus a P2Y12 inhibitor, usually clopidogrel. After 1 year, the patient should be managed with OAC alone. The OAC strategy should be a NOAC (ideally with the potential for less bleeding) or if on warfarin, with goodquality anticoagulation control (TTR $\geq 70 \%$ )

Beyond 1 year, the evidence suggests that OAC monotherapy is the preferred option, given similar or worse major adverse cardiac events and more bleeding with combining NOAC and antiplatelets. ${ }^{99}$ The AFIRE trial included AF patients who underwent $\mathrm{PCI}$ or coronary artery bypass grafting (CABG) more than 1 year earlier or did not require revascularization. ${ }^{100}$ The patients were assigned to receive monotherapy with rivaroxaban $(10 \mathrm{mg}$ o.d. for patients with an eGFR of 15 to $49 \mathrm{~mL} / \mathrm{min}$ or $15 \mathrm{mg}$ o.d. for patients with an eGFR $\geq 50 \mathrm{~mL} / \mathrm{min}$ ) or a combination of rivaroxaban plus a single antiplatelet drug. The incidence of both cardiovascular and noncardiovascular death was lower in the rivaroxaban monotherapy group. For the primary efficacy endpoint (a composite of stroke, SE, myocardial infarction, unstable 


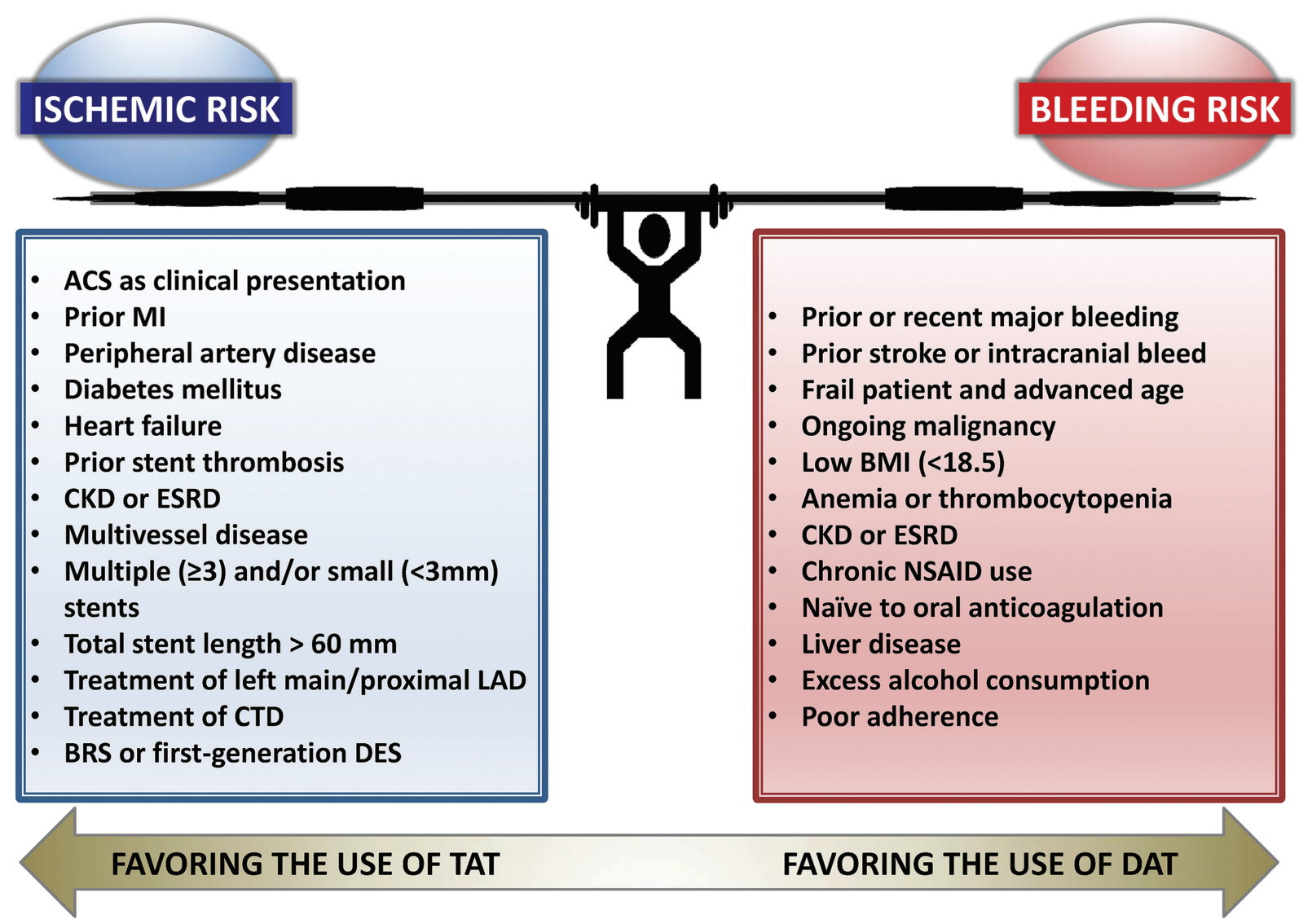

Fig. 11 Factors tipping the balance between ischemic and bleeding risk in AF patients presenting with ACS and/or undergoing PCI. The figure was redrawn and modified from Vitolo et al. ${ }^{90} \mathrm{ACS}$, acute coronary syndrome; AF, atrial fibrillation; BMI, body mass index; BRS, bioresorbable scaffold; CKD, chronic kidney disease; CTO, chronic total occlusion; DAT, dual antithrombotic therapy; DES, drug-eluting stent; ESRD, end-stage renal disease; LAD, left anterior descending artery; MI, myocardial infarction; NSAID, nonsteroidal anti-inflammatory drug; $\mathrm{PCl}$, percutaneous coronary intervention; TAT, triple antithrombotic therapy.

angina requiring revascularization, or death from any cause), monotherapy was noninferior to dual therapy (HR: 0.72, 95\% CI: 0.55-0.95). Additionally, monotherapy decreased major bleeding by $41 \%$. Therefore, monotherapy with rivaroxaban is recommended rather than a combination of rivaroxaban with an antiplatelet drug in AF patients with stable CAD at more than 1 year after a PCI or CABG. Although the AFIRE trial only investigated rivaroxaban at the J-ROCKET AF dosing, it suggests that monotherapy with a NOAC at the stroke prevention dosing without a combination of an antiplatelet drug is favored for AF patients with stable CAD.

\section{Recommendations}

- In AF patients eligible for NOACs, it is recommended to use a NOAC in preference to a VKA in combination with antiplatelet therapy.

- In patients at high bleeding risk (HAS-BLED $\geq 3$ ), rivaroxaban $15 \mathrm{mg}$ o.d. should be considered in preference to rivaroxaban $20 \mathrm{mg}$ o.d. for the duration of concomitant single or DAPT, to mitigate bleeding risk.

- In patients at high bleeding risk (HAS-BLED $\geq 3$ ), dabigatran $110 \mathrm{mg}$ b.i.d. (twice daily) should be considered in preference to dabigatran $150 \mathrm{mg}$ b.i.d. for the duration of concomitant single or DAPT, to mitigate bleeding risk.
- In AF patients with an indication for a VKA in combination with antiplatelet therapy, the VKA dosing should be carefully regulated with a target INR of 2.0 to 2.5 and TTR $>70 \%$.

\section{Patients with ACS}

- In AF patients with ACS undergoing an uncomplicated PCI, early cessation ( $\leq 1$ week) of aspirin and continuation of dual therapy with an OAC and a P2Y12 inhibitor (preferably clopidogrel) for up to 12 months is recommended if the risk of stent thrombosis is low or if concerns about bleeding risk prevail over concerns about risk of stent thrombosis.

- Triple therapy with aspirin, clopidogrel, and an OAC for longer than 1 week after an ACS should be considered when risk of stent thrombosis outweighs the bleeding risk, with the total duration ( $\leq 1$ month) decided according to assessment of these risks.

\section{Elective $\mathrm{PCI}$}

- After uncomplicated PCI for stable CAD, early cessation ( $\leq 1$ week) of aspirin and continuation of dual therapy with OAC for up to 6 months and clopidogrel is recommended if the risk of stent thrombosis is low or if concerns 


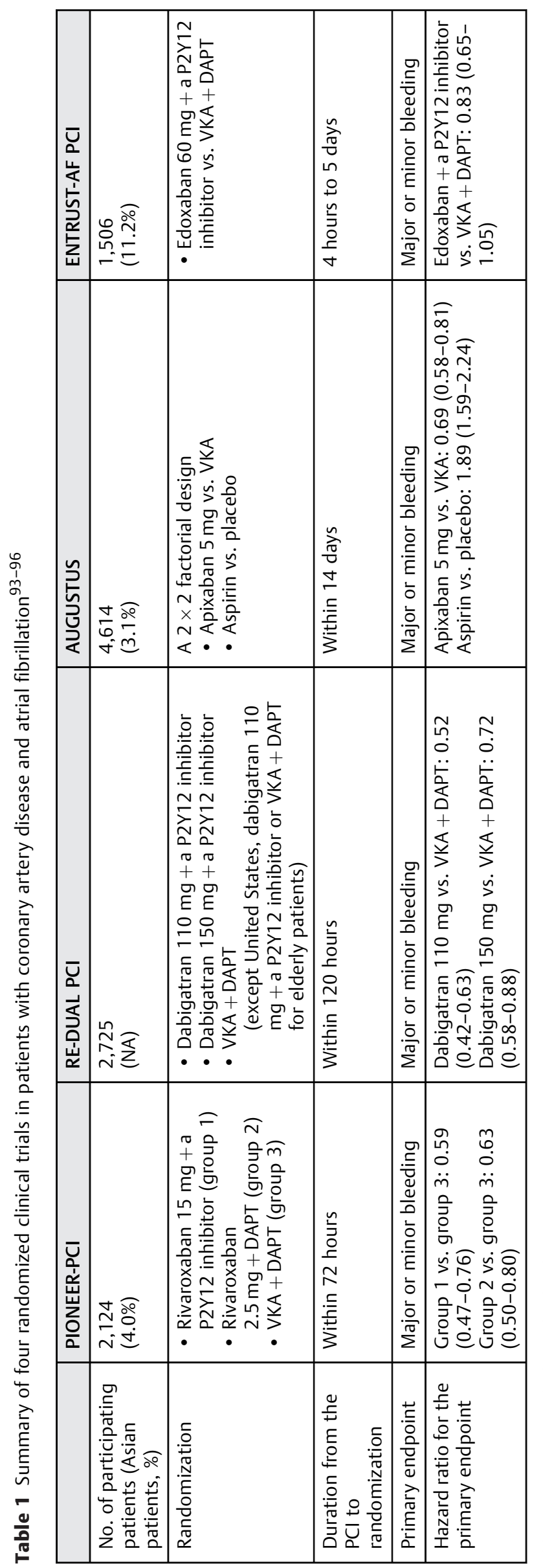

about bleeding risk prevail over concerns about risk of stent thrombosis, irrespective of the type of stent used.

- After uncomplicated PCI for stable CAD, triple therapy with aspirin, clopidogrel, and an OAC for longer than 1 week should be considered when risk of stent thrombosis outweighs the bleeding risk, with the total duration ( $\leq 1$ month) decided according to assessment of these risks.

Stable CAD: In patients with stable CAD, such as more than 1 year after the PCI or CABG, a standard dose of NOAC monotherapy is recommended.

\section{Footnotes}

Risk of stent thrombosis encompasses: (1) risk of thrombosis occurring, and (2) risk of death should stent thrombosis occur, both of which relate to anatomical, procedural, and clinical characteristics. Risk factors for stable CAD (chronic coronary syndrome) patients include: stenting of left main stem or last remaining patent artery; suboptimal stent deployment; stent length $>60 \mathrm{~mm}$; diabetes mellitus; chronic kidney disease; bifurcation with two stents implanted; treatment of chronic total occlusion; and previous stent thrombosis on adequate antithrombotic therapy.

\section{Management of OACs before, during, and after AF Ablation}

Catheter ablation procedures for AF are associated with both prothromboembolic and bleeding risks, and appropriate anticoagulation managements before, during, and after the procedure are quite important. Since the COMPARE randomized study demonstrated lower risks of both thromboembolism and bleeding complications under uninterrupted VKA compared with interrupted VKA with heparin bridging, ${ }^{101}$ it is generally accepted that the procedure should be performed without interrupting VKA, when anticoagulation control is appropriate. ${ }^{102}$

NOACs are currently used in many patients even in those undergoing AF ablation. The Japanese Catheter Ablation Registry of AF (J-CARAF) during 2011 to 2016 showed that of the 9,048 patients with periprocedural oral anticoagulation, 3,231 (35.7\%) were treated with VKA, whereas the other 5,817 (64.3\%) were managed with NOACs. ${ }^{103}$ A metaanalysis of nonrandomized studies showed that interrupted dabigatran for a minimum period (12-24 hours) before the procedure was associated with similar thromboembolism and bleeding complication rates to uninterrupted VKA. ${ }^{104}$

Several randomized, prospective clinical trials on uninterrupted NOACs versus uninterrupted VKA have been conducted (-Table 2). These trials include VENTURE-AF study for rivaroxaban versus VKA ${ }^{105}$; RE-CIRCUIT study for dabigatran versus VKA ${ }^{106}$; AXAFA-AFNET 5 study for apixaban versus $V_{K A}{ }^{107}$; and ELIMINATE-AF study for edoxaban versus VKA. ${ }^{108}$ In these studies, therapeutic doses of NOACs and VKA with target prothrombin time-INR between 2.0 and 3.0 were generally administered for $>3$ weeks before ablation, with exception of short-period administration in some 


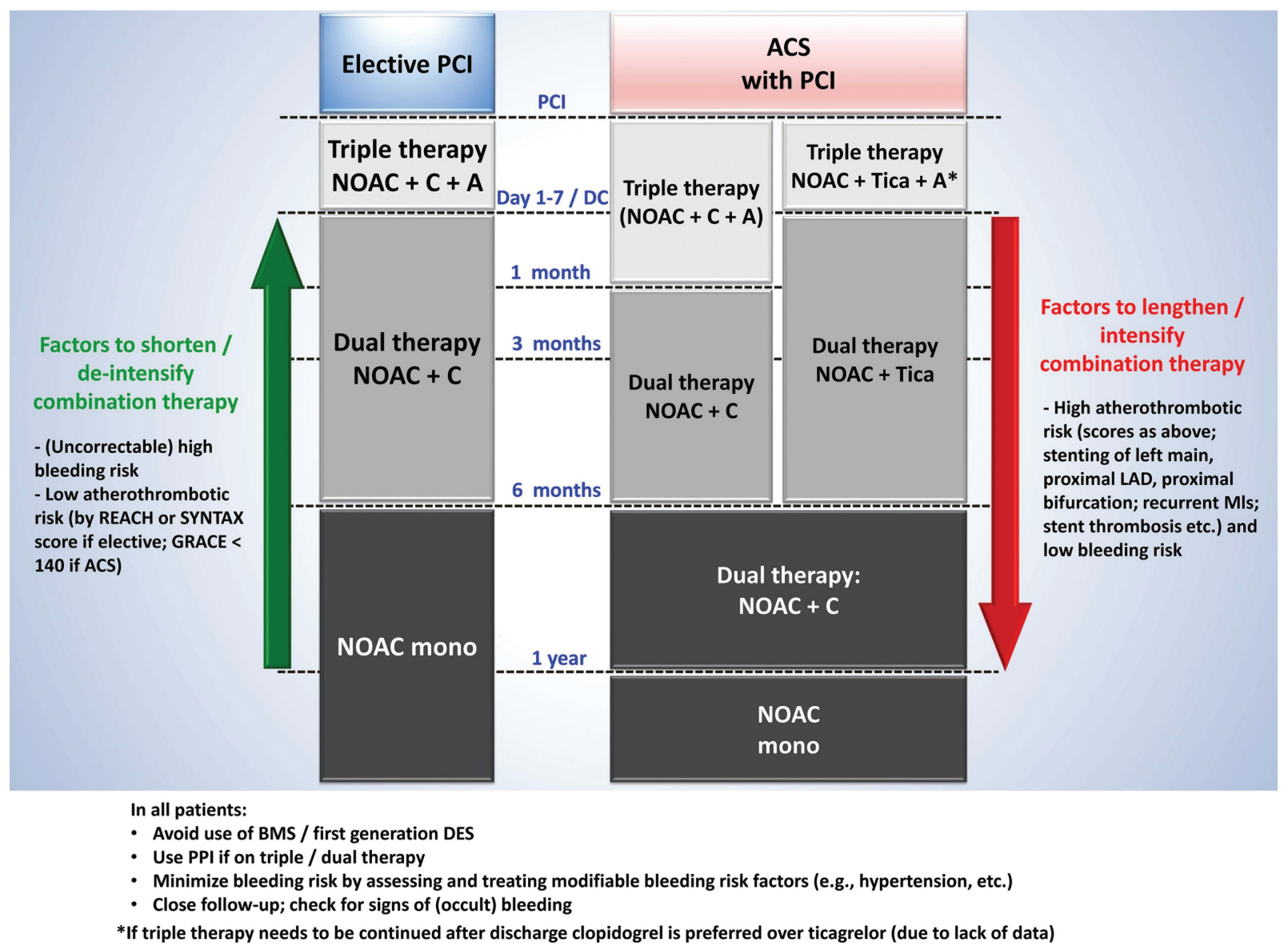

Fig. 12 Anticoagulation therapy after elective PCI or ACS in AF patients. A, aspirin 75-100 mg QD; C, clopidogrel 75 mg QD; Tica, ticagrelor $90 \mathrm{mg}$ BID. The figure was redrawn and modified from the 2021 European Heart Rhythm Association Practical Guide on the use of NOACs in patients with AF by Steffel et al. ${ }^{98}$ ACS, acute coronary syndrome; AF, atrial fibrillation; BID, twice daily; BMS, bare metal stent; DES, drug-eluting stent; LAD, left anterior descending artery; $\mathrm{MI}$, myocardial infarction; NOAC, non-vitamin $\mathrm{K}$ antagonist oral anticoagulant; $\mathrm{PCl}$, percutaneous coronary intervention; PPI, proton pump inhibitor; QD, once daily.

cases in which transesophageal or intracardiac echocardiography confirmed the absence of intra-atrial thrombus. After the ablation procedure, the drugs were continued for $>30$ days. During the procedure, heparin was given to maintain activated clotting time $>300$ seconds in all studies. The RECIRCUIT, ${ }^{106}$ AXAFA-AFNET 5, ${ }^{107}$ and ELIMINATE-AF ${ }^{108}$ studies included patients enrolled from the Asian countries. The incidences of major complications in uninterrupted NOACs versus uninterrupted VKA groups in each study are shown in - Table 2.

In a meta-analysis of these four trials comparing NOACs versus VKA, ${ }^{108}$ the rate of death was 0.1 versus $0.2 \%$; ischemic stroke, 0.2 versus $0.2 \%$; major bleeding, 2.1 versus $4.2 \%$; and the composite outcome, 2.4 versus $4.6 \%$, respectively. Another meta-analysis of six randomized studies ${ }^{109}$ on uninterrupted NOACs (dabigatran, rivaroxaban, and apixaban) versus uninterrupted VKA revealed that the incidence of major bleeding was significantly lower in the NOAC group (1.68\%) than in the VKA group (3.80\%) $(\mathrm{OR}=0.45,95 \% \mathrm{CI}$ : $0.26-0.81, p=0.007$ ); while the incidence of ischemic stroke or transient ischemic attack (TIA) was low and similar between the NOAC $(0.21 \%)$ and VKA groups $(0.21 \%)$. Further, the incidence of silent cerebral thromboembolic events (in three studies) was similar between NOAC (14.0\%) and VKA groups (13.3\%). Similar results were reported by another meta-analysis. ${ }^{110}$

Interrupted NOAC protocols versus uninterrupted regimes have been tested by prospective, randomized studies done in Asian countries. ${ }^{111-114}$ Notwithstanding the small-size study cohorts which may be underpowered for the thromboembolic outcomes, an ablation strategy with minimally interrupted periprocedural NOACs may be an option.

\section{Recommendations}

- We recommend a preferential use of NOACs over VKA because of their safety profile relative to VKA in addition to their ease of management before and after ablation.

- NOAC dosing protocols, uninterrupted or minimally interrupted, should be determined in each institution, depending on the volume of AF ablation done, experience of the operator, back-up system in case of life-threatening complications, baseline renal function and thromboembolism and bleeding risks of each patient, time of administration 
Table 2 Outlines and major outcomes of four randomized trials on NOACs versus VKA for AF ablations ${ }^{105-108}$

\begin{tabular}{|c|c|c|c|c|c|c|c|c|}
\hline & \multicolumn{2}{|l|}{ VENTURE-AF } & \multicolumn{2}{|l|}{ RE-CIRCUIT } & \multicolumn{2}{|c|}{ AXAFA-AFNET } & \multicolumn{2}{|c|}{ ELIMINATE-AF } \\
\hline NOAC & \multicolumn{2}{|l|}{$\begin{array}{l}\text { Rivaroxaban } \\
20 \text { mg QD } \\
\text { (evening) }\end{array}$} & \multicolumn{2}{|l|}{$\begin{array}{l}\text { Dabigatran } \\
150 \text { mg BID }\end{array}$} & \multicolumn{2}{|l|}{$\begin{array}{l}\text { Apixaban } \\
5 \mathrm{mg} \mathrm{BID}\end{array}$} & \multicolumn{2}{|c|}{$\begin{array}{l}\text { Edoxaban } \\
60 \text { mg QDa } \\
\text { (evening) }\end{array}$} \\
\hline Comparator & \multicolumn{2}{|c|}{$\begin{array}{l}\text { VKA } \\
(\text { INR, 2.0-3.0) }\end{array}$} & \multicolumn{2}{|c|}{$\begin{array}{l}\text { VKA } \\
\text { (INR, 2.0-3.0) }\end{array}$} & \multicolumn{2}{|c|}{$\begin{array}{l}\text { VKA } \\
\text { (INR, 2.0-3.0) }\end{array}$} & \multicolumn{2}{|c|}{$\begin{array}{l}\text { VKA } \\
(\text { INR, 2.0-3.0) }\end{array}$} \\
\hline Study design & \multicolumn{2}{|l|}{$\begin{array}{l}\text { Open-label, } \\
\text { randomized }\end{array}$} & \multicolumn{2}{|l|}{$\begin{array}{l}\text { Open-label, } \\
\text { randomized }\end{array}$} & \multicolumn{2}{|c|}{$\begin{array}{l}\text { Open-label, } \\
\text { randomized }\end{array}$} & \multicolumn{2}{|c|}{$\begin{array}{l}\text { Open-label, } \\
\text { randomized }\end{array}$} \\
\hline No. of patients (NOAC vs. VKA) & \multicolumn{2}{|l|}{124 vs. 124} & \multicolumn{2}{|l|}{317 vs. 318} & \multicolumn{2}{|c|}{318 vs. 315} & \multicolumn{2}{|c|}{375 vs. 178} \\
\hline Enrollment from Asian countries & \multicolumn{2}{|l|}{ No } & \multicolumn{2}{|l|}{ Yes } & \multicolumn{2}{|l|}{ Yes } & \multicolumn{2}{|l|}{ Yes } \\
\hline Duration of administration before ablation & \multicolumn{2}{|l|}{$>3$ wk } & \multicolumn{2}{|l|}{$4-8 w k$} & \multicolumn{2}{|l|}{$>30$ days } & \multicolumn{2}{|l|}{$3-4 w k$} \\
\hline Follow-up period after ablation & \multicolumn{2}{|l|}{$>30$ days } & \multicolumn{2}{|l|}{8 weeks } & \multicolumn{2}{|l|}{$>30$ days } & \multicolumn{2}{|l|}{90 days } \\
\hline \multicolumn{9}{|l|}{ Patient characteristics } \\
\hline Mean or median age $(y)$ & \multicolumn{2}{|l|}{$59.6 \pm 10.2$} & \multicolumn{2}{|l|}{$59.1 \pm 10.4$} & $64(58,70$ & & $60.5(53-6$ & \\
\hline Percentage of male patients & $71.0 \%$ & & $74.8 \%$ & & $67.0 \%$ & & $71.5 \%$ & \\
\hline Percentage of paroxysmal AF & $73.4 \%$ & & $67.6 \%$ & & $58.0 \%$ & & $67.6 \%$ & \\
\hline Mean $\mathrm{CHA}_{2} \mathrm{DS}_{2}$-VASc score & 1.6 & & 2.1 & & 2.4 & & $0 / 1$ in 49.8 & \\
\hline Primary endpoints & $\begin{array}{l}\text { ISTH/GUSTO } \\
\text { major bleedi }\end{array}$ & glMI & $\begin{array}{l}\text { ISTH major } \\
\text { bleeding }\end{array}$ & & $\begin{array}{l}\text { All-cause d } \\
\text { stroke, or } \\
\text { bleeding }\end{array}$ & $\begin{array}{l}\text { eath, } \\
\text { najor }\end{array}$ & $\begin{array}{l}\text { All-cause d } \\
\text { stroke (isc) } \\
\text { hemorrhac } \\
\text { undetermi } \\
\text { or ISTH ma } \\
\text { bleeding }\end{array}$ & $\begin{array}{l}\text { eath, } \\
\text { emic, } \\
\text { ic, or } \\
\text { ed), } \\
\text { jor }\end{array}$ \\
\hline Major complication rates & Rivaroxaban & VKA & Dabigatran & VKA & Apixaban & VKA & Edoxaban & VKA \\
\hline ISTH major bleeding & $0 \%$ & $0.8 \%$ & $1.6 \%$ & $6.9 \%$ & $3.1 \%$ & $4.4 \%$ & $2.4 \%$ & $1.7 \%$ \\
\hline Ischemic stroke & $0 \%$ & $0.8 \%$ & $0 \%$ & $0.3 \%$ & $0.6 \%$ & $0 \%$ & $0.3 \%$ & $0 \%$ \\
\hline Death & $0 \%$ & $0.8 \%$ & $0 \%$ & $0 \%$ & $0.3 \%$ & $0.3 \%$ & $0 \%$ & $0 \%$ \\
\hline Composite & $0 \%$ & $2.4 \%$ & $1.6 \%$ & $7.2 \%$ & $4.0 \%$ & $4.7 \%$ & $2.7 \%$ & $1.7 \%$ \\
\hline
\end{tabular}

Abbreviations: AF, atrial fibrillation; BID, twice daily; INR, international normalized ratio; NOACs, non-vitamin K antagonist oral anticoagulants; QD, once daily; VKA, vitamin $\mathrm{K}$ antagonist.

${ }^{a}$ Dose reduced when dose reduction criteria were met.

of once-daily NOACs (morning or evening), preparation of specific antidotes to NOACs, etc. ( - Fig. 13).

- For most patients, an uninterrupted NOAC strategy may be the preferred option.

- When VKA is used, it should be controlled within a therapeutic range and uninterrupted throughout the periprocedural period unless bleeding events preclude its continuous use.

- In general, OAC therapy is continued for 2 months following ablation in all patients. Beyond this time, a decision to continue OAC long term is determined primarily by the presence of $\mathrm{CHA}_{2} \mathrm{DS}_{2}$-VASc stroke risk factors rather than the rhythm status.

\section{Reversal Agents}

The general principles of managements of bleeding are summarized in - Fig. 14. For severe bleeding or life-threat- ening bleeding, reversal agents could be considered to reverse the anticoagulant effects of NOACs.

Idarucizumab is a monoclonal antibody fragment and binds dabigatran with an affinity that is 350 times as high as that observed with thrombin. ${ }^{115}$ In the RE-VERSE AD study, the efficacy and safety of idarucizumab was tested in patients who had serious bleeding or required urgent procedures. In an interim analysis of the first 90 patients, idarucizumab reversed the anticoagulant effect of dabigatran within minutes in 88 to $98 \%$ of patients. ${ }^{116}$ In the whole cohort of 503 patients, the median time to cessation of bleeding was 2.5 hours in those with uncontrolled bleeding who could be assessed. ${ }^{117}$ For the periprocedural group, the median time to the initiation of the intended procedure was 1.6 hours. Periprocedural hemostasis was assessed as normal in $93.4 \%$ of the patients, mildly abnormal in $5.1 \%$, and moderately abnormal in $1.5 \%$. At 90 days, thrombotic events had occurred in $6.3 \%$ of the patients in the uncontrolled 


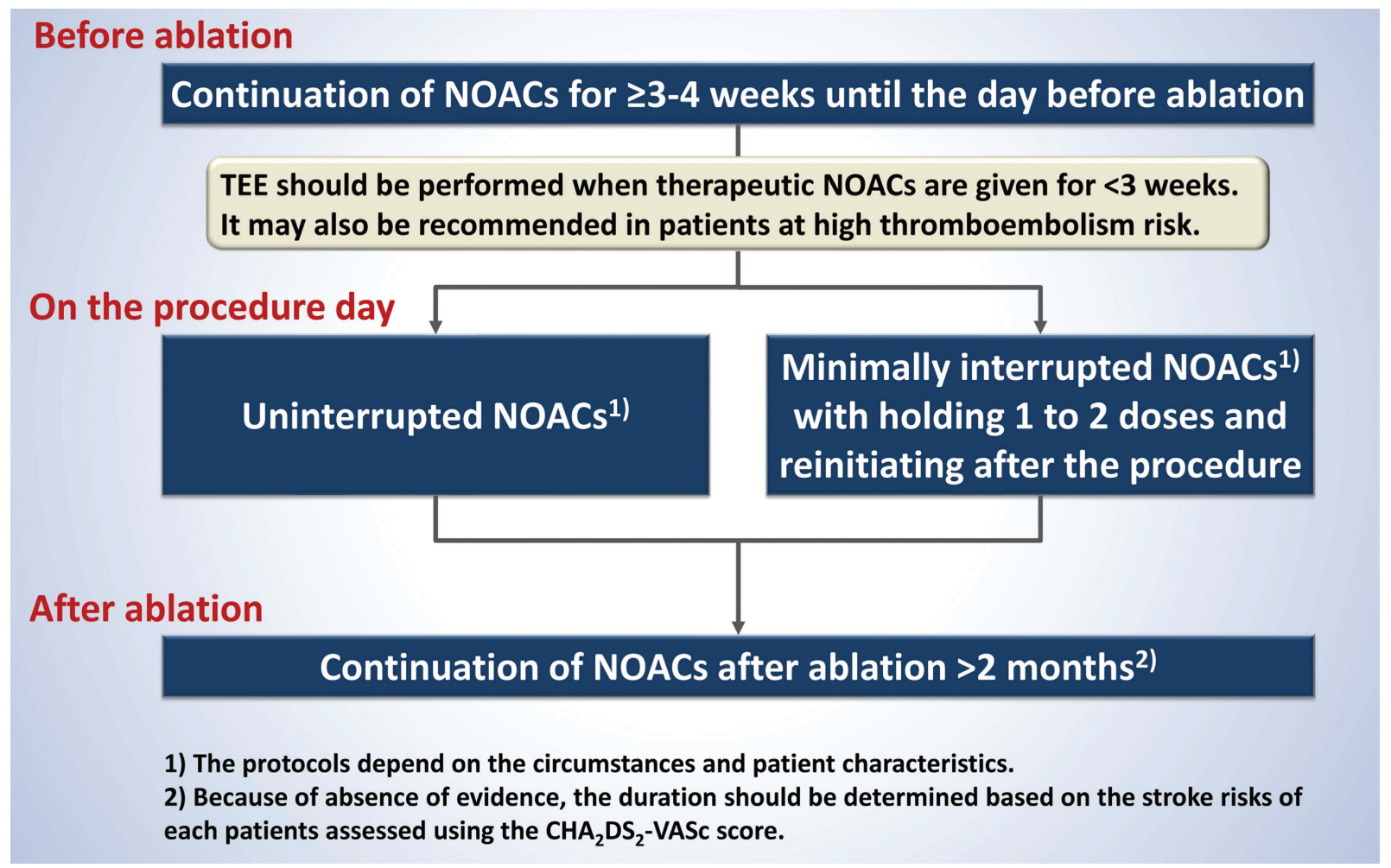

Fig. 13 A flow chart about the general recommendation for NOACs in the periprocedural period of catheter ablation. NOACs, non-vitamin $\mathrm{K}$ antagonist oral anticoagulants; TEE, transesophageal echocardiography.

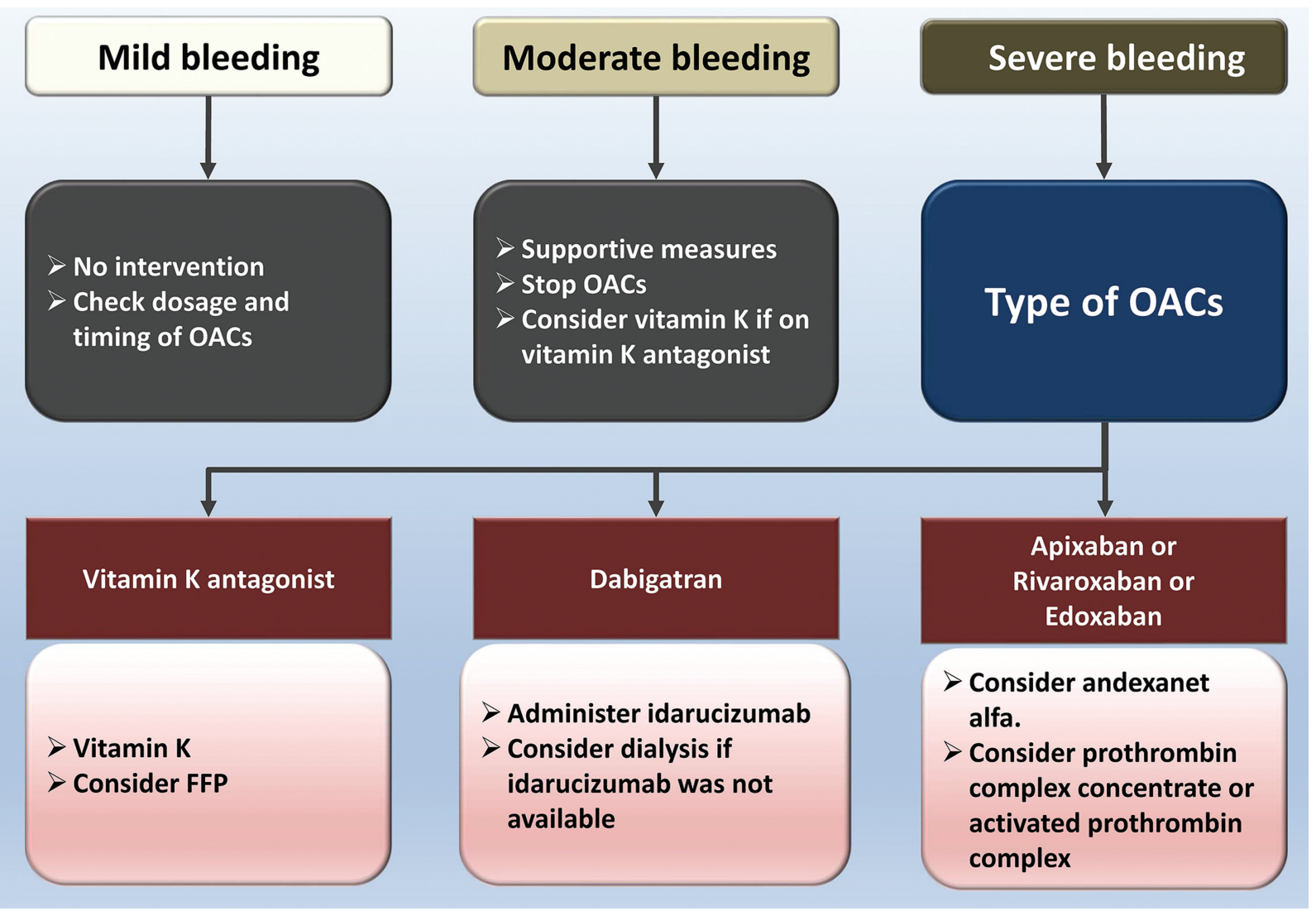

Fig. 14 General principles of managements of bleeding for anticoagulated AF patients. AF, atrial fibrillation; FFP, fresh frozen plasma; NOACs, non-vitamin $\mathrm{K}$ antagonist oral anticoagulants; OACs, oral anticoagulants. 
bleeding group and in $7.4 \%$ in the periprocedural group, while the mortality rate was 18.8 and $18.9 \%$, respectively. No serious adverse safety signals were noted. More recently, it was found that although both dabigatran and idarucizumab were renally cleared, impaired renal function did not affect the reversal of anticoagulation. ${ }^{118}$ The REVERSE-AD study results were consistent and supported by observations from a post-approval global registry (RE-VECTO), which also showed that off-label use was minimal. ${ }^{119}$ Idarucizumab is approved in many countries for patients treated with dabigatran when reversal of the anticoagulant effects of dabigatran is needed for emergency surgery/urgent procedures and in life-threatening or uncontrolled bleeding.

Andexanet alfa is a recombinant modified human factor Xa decoy protein that is catalytically inactive but which retains the ability to bind factor Xa inhibitors in the active site with high affinity. ${ }^{120}$ In a clinical study of older healthy volunteers, andexanet reversed the anticoagulant activity of apixaban and rivaroxaban within minutes after administration and for the duration of infusion, without clinical evidence of toxic effects. ${ }^{121}$ In the multicenter, open label, single-arm ANNEXA-4 trial, 352 patients with acute major bleeding associated with factor Xa inhibitors (mostly on rivaroxaban and apixaban) were given an initial bolus and subsequent 2 hour infusion of andexanet alfa. This substantially reduced anti-factor Xa activity after the bolus (75-92\%) and this effect persisted till the end of the infusion. Good or excellent hemostatic efficacy was achieved in $82 \%, 12$ hours after the infusion. ${ }^{122}$ During 30 days of follow-up, 49 patients (14\%) died and 34 (10\%) experienced a thrombotic event. Similar data are based on an earlier interim analysis of this study, ${ }^{121}$ and andexanet alfa was granted accelerated approval by the Food and Drug Administration for the reversal of anticoagulation if needed due to life-threatening or uncontrolled bleeding in patients treated with apixaban or rivaroxaban.

When managing OAC-related bleeding, it is important to survey for occult malignancies that are the cause/origin of the bleeding, e.g., GI tract cancer in patients with GI bleeding. ${ }^{84}$ In a nationwide study from Taiwan, incident GI cancers were diagnosed in 1 of $37 \mathrm{AF}$ patients at 1 year after OAC-related GI bleeding, and were more common among patients treated with NOACs $(1 / 26)$ compared with warfarin $(1 / 41) .{ }^{123}$ Interestingly, the risk of mortality after GI tract cancers were diagnosed was lower in patients treated with NOACs than in those treated with warfarin ( 23.5 vs. $51.8 \%$; aHR: $0.441 ; p<.001)$, and more patients treated with NOACs (33.8\%) underwent surgery than those treated with warfarin (18.9\%), suggesting that NOACs may serve as a stronger "screening test" than warfarin and may be able to disclose GI cancers at an earlier stage when operation is possible, therefore leading to a better prognosis. ${ }^{123}$ Similar findings have been reported for anticoagulated patients presenting with hematuria among whom the possibility of underlying bladder cancers should be kept in mind. ${ }^{124}$

\section{Recommendations}

- Idarucizumab is indicated for the reversal of dabigatran in patients with serious bleeding or requiring urgent procedures.
- Andexanet alfa can be useful for reversing anticoagulation in patients treated with factor Xa inhibitors with lifethreatening or uncontrolled bleeding.

- The possibility of occult malignancies that are the cause/origin of the bleeding should be kept in mind when managing OAC-related bleeding.

\section{Stroke Prevention in Special Patient Groups}

Issues about stroke prevention in special patient groups are discussed in the Supplementary Material (available in the online version).

\section{Left Atrial Appendage Occlusion}

The efficacy, safety, and procedural aspects, as well as the limitations of current data on left atrial appendage (LAA) occlusion have recently been the subject of a detailed expert consensus statement: EHRA/EAPCI (European Association of Percutaneous Cardiovascular Interventions) on catheterbased LAA occlusion. ${ }^{125}$ More recently, the role of surgical occlusion of the LAA in AF patients undergoing cardiac surgery has gained prominence with publication of the LAAOS III trial. ${ }^{126}$ The latter showed that stroke/SE occurred in $4.8 \%$ in the LAA occlusion group and in $7.0 \%$ in the noocclusion group (HR: $0.67 ; 95 \% \mathrm{Cl}: 0.53-0.85 ; p=0.001$ ). The incidence of perioperative bleeding, heart failure, or death did not differ significantly between the trial groups. Thus, among participants with $\mathrm{AF}$ who had undergone cardiac surgery, the risk of ischemic stroke or SE was lower with concomitant LAA occlusion performed during the surgery than without it.

\section{Catheter-Based LAA Occlusion}

\section{Efficacy}

There are two randomized controlled trials (RCTs) comparing percutaneous LAA occlusion with the Watchman device to warfarin in patients with NVAF and high risk of stroke. ${ }^{127,128}$ Data from these and their associated registries ${ }^{129,130}$ demonstrate noninferiority to warfarin for prevention of ischemic stroke or $\mathrm{SE}>7$ days postprocedure. There were more ischemic strokes in the device group (1.6 vs. 0.9 events $/ 100$ patient-years, $p=0.05$ ), largely driven by procedure-related strokes, and a significant reduction in hemorrhagic stroke $(0.15$ vs. $0.96 / 100$ patient-years, $p=0.004) .{ }^{130}$ To date, there are limited data comparing LAA occlusion devices with NOACs. Noninferiority to NOACs has been examined in the PRAGUE-17 trial, ClinicalTrials.gov identifier NCT02426944, ${ }^{131}$ which showed that in AF patients at high risk for stroke $\left(\mathrm{CHA}_{2} \mathrm{DS}_{2}\right.$-VASc: $\left.4.7 \pm 1.5\right)$ and increased risk of bleeding, LAAO was noninferior to NOACs in preventing major AF-related cardiovascular, neurological, and bleeding events. There were no differences between groups for the components of the composite endpoint: all-stroke/TIA (subdistribution HR [sHR]: $1.00 ; 95 \% \mathrm{CI}$ : $0.40-2.51$ ), clinically significant bleeding (sHR: $0.81 ; 95 \% \mathrm{CI}$ : 0.44-1.52), and cardiovascular death (sHR: $0.75 ; 95 \% \mathrm{CI}$ : 
0.34-1.62). Major LAAC-related complications occurred in 9 (4.5\%) patients. ${ }^{132}$

Safety

Safety data are available from the RCTs ${ }^{127,128}$ and several registries, ${ }^{129,133-135}$ including two conducted in the AsiaPacific region. ${ }^{136,137}$ In modern practice, there is high implantation success of 95 to $98.5 \%$. $28,133,137$

Procedure- and device-related complications in the first 7 days were high in the earlier PROTECT AF trial ${ }^{127}$ at $8.7 \%$ but lower at $4.2 \%$ in the subsequent PREVAIL trial. ${ }^{128}$ Similar reduction in complication rate has been seen over time in registries, with early data showing a high complication rate of $8.6 \%{ }^{138}$ reducing to 2.2 to $3 \%$ for more contemporaneous registries. ${ }^{128,133,137}$ However, trials and registries have selection bias and real-world data suggest that the complication rate may be significantly higher. ${ }^{139}$

The rates of early device thrombosis in meta-analysis and registry data are 3.7 to $3.9 \%, 135,140$ and there are no RCTs to guide the duration of anticoagulation and number, and type and duration of antiplatelet agents, although registry data suggest safety of a single antiplatelet agent. Other "realworld" reports of device-related thrombus (DRT) suggest incidence rates as high as $7.2 \%$ per year, ${ }^{141}$ as well as high annual rates of mortality (7.4\%), ischemic strokes (4.3\%), and major hemorrhages (4.5\%). ${ }^{142}$ The EUROC-DRT registry reported that substantial proportion of DRT (18\%) was detected $>6$ months after LAA closure, highlighting the need for imaging follow-up, especially since such patients were at high risk for stroke and mortality (13.8 and 20.0\%, respectively). ${ }^{143}$

Although there are registry data on safety of LAA occlusion in patients with a contraindication to anticoagulation, ${ }^{135}$ there are no published RCT data on efficacy and safety of LAA occlusion devices in this cohort, although ongoing studies may address this. ${ }^{125,144}$

\section{Issues Specific to the Asia-Pacific Region}

Asians are significantly underrepresented in clinical trials and registries of LAA occlusion devices with $<1 \%$ of patients in the PROTECT-AF and PREVAIL trials and associated registries being of Asian ethnicity. ${ }^{130}$ However, evidence for safety and efficacy in Asian patients come from two small registries from the Asia-Pacific region-the WASP registry ${ }^{137}$ performed in South-East Asia and Australia with 106/203 patients being of Asian ethnicity and the SALUTE registry of 54 patients in Japan. ${ }^{136}$ The WASP registry suggested important differences in anatomy and need for larger device sizes in Asian patients. ${ }^{136}$

The lack of comparative data to NOACs may be especially pertinent in the Asia-Pacific region given the more profound benefits of NOACs in Asian populations, especially with respect to reduced incidence of intracranial hemorrhage. 65

Finally, cost-effectiveness analysis has been performed utilizing health care costs from the United States, ${ }^{145,146}$ which may not be applicable in the Asia-Pacific region, especially when one considers the diverse health care systems, costs, and funding models across the region.

\section{Recommendations}

- LAA occlusion may be considered for stroke prevention in patients with AF and clear contraindications for long-term anticoagulant treatment (e.g., intracranial bleeding without a reversible cause).

- Surgical occlusion or exclusion of the LAA is recommended for stroke prevention in patients with AF undergoing cardiac surgery.

\section{Role of Environmental and Lifestyle Factors in $\mathbf{A F}$}

Cardiovascular risk factors, including lifestyle factors and comorbidities, affect the risk and prognosis of AF. Management of these risk factors, unhealthy lifestyle behaviors and practices, and comorbidities is important for stroke prevention and to control the burden of AF and symptoms associated with AF. This strategy constitutes the " $\mathrm{C}$ " component of the $A B C$ pathway. ${ }^{11}$ Lifestyle modifications, including weight loss, physical activity, alcohol abstinence, and risk factor modifications including BP control, have been shown to reduce AF burden. ${ }^{147-154}$

Unhealthy lifestyle factors tend to cluster together, and increased numbers of unhealthy lifestyle factors (current smoking, heavy drinking [ $>30 \mathrm{~g} /$ day], and lack of regular exercise) have been associated with a higher risk of incident AF. ${ }^{155,156}$ Overall, the promotion of a healthy lifestyle to lower the risk of new-onset AF and AF-related complications is recommended.

\section{Body Weight: Role of Obesity and Low Body Weight}

Obesity is an important and potentially modifiable risk factor for $\mathrm{AF}$ and can affect the incidence and persistence of AF. ${ }^{157,158}$ Obesity is also associated with other cardiovascular disease risks, including hypertension, sleep apnea, impaired glucose tolerance, and diabetes, which are all associated with incident AF and AF-related complications.

Aggressive weight reduction and risk factor modification have been shown to reduce AF recurrences and arrhythmia burden, as well as AF symptom burden; thus, there is improved maintenance of sinus rhythm and beneficial effects on cardiac remodeling compared with conventional therapy in patients with obesity. ${ }^{148,149,159,160}$ For example, in patients diagnosed with overweight or obesity concomitant with $\mathrm{AF},>10 \%$ weight reduction was associated with reduction in the AF burden and reversal of AF type and natural progression. ${ }^{149,161}$ Underweight patients are not uncommon in the Asian population, and these patients show an increased risk of AF. ${ }^{162}$ Moreover, fluctuations in body weight were associated with an increased risk of AF, particularly amongst those with low body weight. ${ }^{163}$

With regard to clinical outcomes, the risk of the composite outcome of ischemic stroke, thromboembolism, or death is 
higher in those with overweight and obesity, even after adjustment for $\mathrm{CHA}_{2} \mathrm{DS}_{2}$-VASc scores. ${ }^{164}$ However, in a systematic review and meta-analysis, an obesity paradox was observed in patients with AF taking anticoagulation therapy, particularly with regard to all-cause and cardiovascular death in subgroup analyses of randomized trial cohorts. ${ }^{165}$ Another study showed that the risk of ischemic stroke, major bleeding, and mortality was lower in Asian patients with AF, who showed a high body mass index and received OACs compared with those with normal weight, whereas underweight patients had an increased risk of mortality and composite outcome compared with those with normal weight. ${ }^{166}$ For stroke prevention, NOACs are generally associated with better outcomes than those with warfarin administration in Asians across patients of different body weights, particularly in underweight patients. ${ }^{76}$ Given the observed obesity paradox in AF patients, keeping a normal body weight is recommended.

\section{Alcohol}

Excessive alcohol consumption is a well-known risk factor and trigger for $\mathrm{AF}^{167}$ Excessive alcohol consumption acts synergistically with other lifestyle risk factors for AF, including hypertension, obesity, obstructive sleep apnea, and cardiomyopathy to magnify their effects. Excessive alcohol consumption is a known clinical risk factor for bleeding during anticoagulation therapy, and is included in the HAS-BLED score. ${ }^{168}$ High alcohol consumption is also associated with an increased risk of thromboembolism and death in patients with incident AF. ${ }^{169}$ Asian data have shown that high alcohol consumption was associated with a high ischemic stroke risk. ${ }^{170}$

One recent randomized trial has reported that alcohol abstinence reduced the risk of recurrent AF in those with heavy alcohol consumption patterns. ${ }^{171}$ Alcohol abstinence was also associated with a low risk of incident AF in patients with newly diagnosed type 2 diabetes, ${ }^{172}$ and alcohol abstinence after a diagnosis of AF was associated with a low risk of ischemic stroke. ${ }^{170}$

\section{Smoking}

Smoking is associated with an increased risk of incident $\mathrm{AF},{ }^{173,174}$ and smoking cessation seems to lower the risk of AF compared with current smokers. ${ }^{173,174}$ In Asian AF patients with a low $\mathrm{CHA}_{2} \mathrm{DS}_{2}$-VASc score, smoking was identified as a risk factor for ischemic stroke. ${ }^{175}$ Furthermore, quitting smoke after incident AF was associated with a low risk of ischemic stroke, lower stroke severity, and death from cerebrovascular events. ${ }^{176}$

\section{Air pollution}

Epidemiological studies have suggested that elevated ambient particulate matter $(\mathrm{PM})<2.5 \mu \mu \mathrm{m}\left(\mathrm{PM}_{2.5}\right)$ or $<10 \mu \mu \mathrm{m}$ $\left(\mathrm{PM}_{10}\right)$ in aerodynamic diameter is consistently associated with adverse cardiac events. In the Asian general population, long-term exposure of PM2.5 is associated with the increased incidence of new-onset $\mathrm{AF} .^{177,178}$

\section{Physical Activity}

Moderate-intensity exercise (150 min/week) or vigorousintensity exercise ( $75 \mathrm{~min} /$ week) recommended by the 2018 Physical Activity Guidelines Advisory Committee is known to improve cardiovascular health. Physical inactivity is associated with an increased risk of incident $\mathrm{AF},{ }^{179}$ and regular exercise could reduce $\mathrm{AF}$ burden and improve AF-related symptoms and patients' quality of life. ${ }^{180-183}$ However, the risk of AF increased in those who participate in extreme endurance exercise that far exceeds the levels recommended by the Physical Activity Guidelines Advisory Committee report. ${ }^{184}$ Cardiorespiratory fitness generally reduces the AF burden and symptom severity in patients with obesity and concomitant $A F$, which may be attributable to the beneficial effects of weight loss. $^{147}$

One recent observational study in Asian patient with incident AF reported that regular exercise was associated with low risks of heart failure, mortality, and dementia in addition to a marginal benefit on ischemic stroke. ${ }^{185,186}$ Regular moderate exercise (170-240 min/week) showed maximal cardiovascular benefits in patients who initiated exercise after diagnosis of AF. Patients who initiated or continued regular exercise after diagnosis of AF were associated with a lower risk of dementia than persistent nonexercisers, with no risk reduction associated with exercise cessation. $^{186}$

\section{Recommendations}

- The promotion of a healthy lifestyle (smoking cessation, reduced alcohol consumption, regular exercise) is recommended to lower the risk of new-onset AF and AF-related complications.

- Appropriate weight control is an important strategy to improve outcomes in patients with AF.

- Reduced consumption or alcohol abstinence is recommended in AF patients with moderate-to-high levels of alcohol use to minimize AF burden and stroke risk.

- Smoking cessation is recommended in patients with AF to reduce the stroke risk, even in those categorized as lowrisk patients based on the $\mathrm{CHA}_{2} \mathrm{DS}_{2}$-VASc score.

- Regular exercise based on the recommendations of the 2018 Physical Activity Guidelines Advisory Committee (150 min/week of moderate-intensity exercise or 75 min/week of vigorous-intensity exercise) can improve cardiovascular outcomes in patients with AF (-Fig. 15).

\section{OAC Use in AF Patients during the COVID-19 Pandemic}

$\mathrm{AF}$ is a common clinical manifestation in hospitalized patients with coronavirus disease 2019 (COVID-19) infection and is associated with a higher risk of mortality and/or requirement for intensive care. ${ }^{187-190}$ The latter is perhaps 


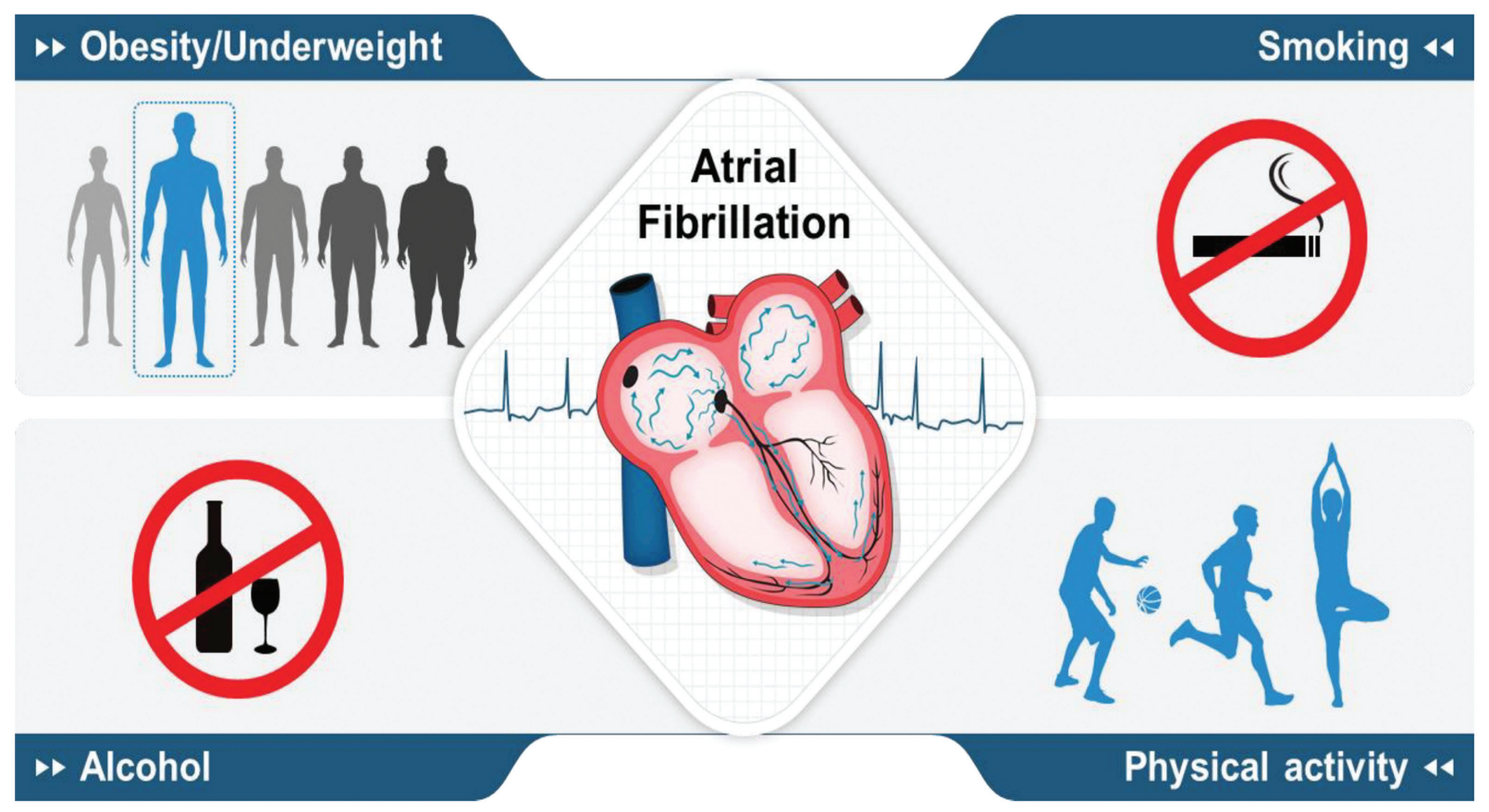

Fig. 15 The integration of lifestyle management in patients with AF. AF, atrial fibrillation.

unsurprising given the higher risk of adverse outcomes in COVID-19 with associated cardiovascular comorbidities. ${ }^{190}$

During the COVID-19 pandemic, TTR values associated with VKA (e.g., warfarin) treatment may be suboptimal with the lack of INR monitoring, and in appropriate patients, a switch to NOACs may be appropriate. ${ }^{191}$ Furthermore, the anticoagulated AF patients may not seek medical help even in the case of bleeding. ${ }^{192}$ Thus, for the outpatients during the COVID-19 pandemic (during the lockdown phase or discharge after recovery from COVID-19 infection), NOAC therapy in replacement of VKA (except for the absolute contraindications of NOACs like prosthetic mechanical valve or moderate-to-severe mitral stenosis) is recommended to minimize the necessity for frequent clinic/office visits for INR monitoring and contact with health care workers. ${ }^{193}$ Remote anticoagulation management/monitoring for elderly patients with NVAF receiving NOACs during the COVID-19 pandemic was associated with a reduction in bleeding complications and delays in the first outpatient revisit after discharge. ${ }^{194}$

COVID-19 is associated with a prothrombotic state, perhaps due to cytokines and immunothrombosis. ${ }^{195}$ For patients already treated with NOACs or VKA and infected with COVID-19 and particularly in the case of severe infection requiring hospitalization, patients should ideally continue their anticoagulation rather than discontinue, although outcome data are conflicting. ${ }^{196-199}$

Conversion from NOAC or VKA into low-molecular-weight heparin (LMWH) during the hospitalization course (especially if severely affected, requiring intensive care unit admission) may be preferable due to less drug interaction with antiviral drugs (e.g., remdesivir) or immunomodulating drugs (e.g., dexamethasone, baricitinib, or tocilizumab), and a higher risk of clinical deterioration due to severe COVID-19 infection (particularly of coagulation and renal function). ${ }^{193,195}$ It would therefore be reasonable to shift NOACs into alternative LMWH for patients with severe COVID-19 infection as long as antiviral agents are deemed necessary and until discharge. LMWH regimes have been tested in recent clinical trials of hospitalized COVID-19 patients but showed conflicting results. ${ }^{200-204}$ For example, in noncritically ill patients with COVID-19, the ATTACC, ACTIV-4a, and REMAP-CAP investigators found that an initial strategy of therapeutic-dose anticoagulation with heparin increased the probability of survival to hospital discharge with reduced use of cardiovascular or respiratory organ support as compared with usual-care thromboprophylaxis. ${ }^{201}$ However, in patients hospitalized with COVID-19 and elevated D-dimer concentration, in-hospital therapeutic anticoagulation with rivaroxaban or enoxaparin followed by rivaroxaban to day 30 did not improve clinical outcomes and increased bleeding compared with prophylactic anticoagulation in the ACTION trial. ${ }^{204}$ Besides, these studies did not specifically enroll AF patients, and therefore, data about the optimal dosage of LMWH for hospitalized AF COVID-19 patients were very limited.

COVID-19 vaccines are usually administered by intramuscular injection, and are an important part of our pandemic response. $^{205}$ An opportunity to screen for AF amongst attendees for vaccination has been promoted. ${ }^{206}$ In $\mathrm{AF}$ patients treated with NOACs, it is advisable to follow the scheme for "minor risk" interventions, and therefore, it is not necessary to withhold any NOAC dosage before and after the injection procedure. ${ }^{207}$ However, it is recommended to use a fine-gauge needle for injection, and apply firm pressure for 5 to 10 minutes after the injection. If the scheduled NOAC 
dosage is close to the injection time before, the scheduled NOAC dosage may be postponed until after the injection if no progression of local hematoma noted.

\section{Recommendations}

- For outpatients with AF during the COVID-19 pandemic, NOAC therapy as a replacement of VKA (unless contraindicated) may be considered.

- For AF patients already treated with NOACs or VKA and infected with COVID-19 and particularly in case of severe infection requiring hospitalization or critical care, conversion from NOAC or VKA into LMWH during the hospitalization course of COVID-19 infection may be considered.

- In AF patients taking NOACs and planned to receive COVID-19 vaccine injection, it is advisable to follow the scheme for "minor risk" interventions, and therefore, it is not necessary to withhold any NOAC dosage before and after the injection procedure.

\section{Conflict of Interest}

B.J.: Served as a speaker for Bayer, BMS/Pfizer, Medtronic, and Daiichi-Sankyo and received research funds from Samjin, Medtronic, and Abbott. No fees have been received directly or personally. Y.T.: Research grants from Medtronic Japan, Boston Scientific, Japan Lifeline, WIN International, Abbott and Biosense-Webster, and speaker honoraria from Abbott and Biosense-Webster. G.Y. H. L.: Consultant and speaker for BMS/Pfizer, Boehringer Ingelheim, and Daiichi-Sankyo. No fees are received personally. The other authors report no conflict of interest.

\section{References}

1 Zhang J, Johnsen SP, Guo Y, Lip GYH. Epidemiology of atrial fibrillation: geographic/ecological risk factors, age, sex, genetics. Card Electrophysiol Clin 2021;13(01):1-23

2 Chao TF, Liu CJ, Tuan TC, et al. Lifetime risks, projected numbers, and adverse outcomes in Asian patients with atrial fibrillation: a report from the Taiwan nationwide AF cohort study. Chest 2018; 153(02):453-466

3 Kim D, Yang PS, Jang E, et al. 10-year nationwide trends of the incidence, prevalence, and adverse outcomes of non-valvular atrial fibrillation nationwide health insurance data covering the entire Korean population. Am Heart J 2018;202:20-26

4 Bai Y, Wang YL, Shantsila A, Lip GYH. The global burden of atrial fibrillation and stroke: a systematic review of the clinical epidemiology of atrial fibrillation in Asia. Chest 2017;152(04): 810-820

5 Chao TF, Chiang CE, Lin YJ, et al. Evolving changes of the use of oral anticoagulants and outcomes in patients with newly diagnosed atrial fibrillation in Taiwan. Circulation 2018;138(14): $1485-1487$

6 Chao TF, Joung B, Takahashi Y, et al. 2021 Focused update of the 2017 consensus guidelines of the Asia Pacific Heart Rhythm Society (APHRS) on stroke prevention in atrial fibrillation. J Arrhythm 2021. Doi: 10.1016/j.ijid.2021.06.051

7 Lip GYH. The ABC pathway: an integrated approach to improve AF management. Nat Rev Cardiol 2017;14(11):627-628

8 Romiti GF, Pastori D, Rivera-Caravaca JM, et al. Adherence to the 'Atrial Fibrillation Better Care' pathway in patients with atrial fibrillation: impact on clinical outcomes-a systematic review and meta-analysis of 285,000 patients. Thromb Haemost 2021. Doi: 10.1055/a-1515-9630

9 Lip GYH, Banerjee A, Boriani G, et al. Antithrombotic therapy for atrial fibrillation: CHEST guideline and expert panel report. Chest 2018;154(05):1121-1201

10 Joung B, Lee JM, Lee KH, et al; KHRS Atrial Fibrillation Guideline Working Group. 2018 Korean guideline of atrial fibrillation management. Korean Circ J 2018;48(12):1033-1080

11 Hindricks G, Potpara T, Dagres N, et al; ESC Scientific Document Group. 2020 ESC Guidelines for the diagnosis and management of atrial fibrillation developed in collaboration with the European Association for Cardio-Thoracic Surgery (EACTS): The Task Force for the diagnosis and management of atrial fibrillation of the European Society of Cardiology (ESC) developed with the special contribution of the European Heart Rhythm Association (EHRA) of the ESC. Eur Heart J 2021;42(05):373-498

12 Chiang CE, Okumura K, Zhang S, et al. 2017 consensus of the Asia Pacific Heart Rhythm Society on stroke prevention in atrial fibrillation. J Arrhythm 2017;33(04):345-367

13 Chao TF, Liu CJ, Wang KL, et al. Using the CHA2DS2-VASc score for refining stroke risk stratification in 'low-risk' Asian patients with atrial fibrillation. J Am Coll Cardiol 2014;64(16):1658-1665

14 Xiong Q, Chen S, Senoo K, Proietti M, Hong K, Lip GY. The CHADS2 and CHA2DS2-VASc scores for predicting ischemic stroke among East Asian patients with atrial fibrillation: a systemic review and meta-analysis. Int J Cardiol 2015;195:237-242

15 Chao TF, Liu CJ, Tuan TC, et al. Comparisons of CHADS2 and CHA2DS2-VASc scores for stroke risk stratification in atrial fibrillation: which scoring system should be used for Asians? Heart Rhythm 2016;13(01):46-53

16 Kang SH, Choi EK, Han KD, et al. Risk of ischemic stroke in patients with non-valvular atrial fibrillation not receiving oral anticoagulants - Korean nationwide population-based study. Circ J 2017;81(08):1158-1164

$17 \mathrm{Kim} \mathrm{TH}$, Yang PS, Uhm JS, et al. $\mathrm{CHA}_{2} \mathrm{DS}_{2}$-VASc score (congestive heart failure, hypertension, age $\geq 75$ [doubled], diabetes mellitus, prior stroke or transient ischemic attack [doubled], vascular disease, age 65-74, female) for stroke in Asian patients with atrial fibrillation: a Korean nationwide sample cohort study. Stroke 2017;48(06):1524-1530

$18 \mathrm{Kim} \mathrm{TH}$, Yang PS, Kim D, et al. $\mathrm{CHA}_{2} \mathrm{DS}_{2}$-VASc score for identifying truly low-risk atrial fibrillation for stroke: a Korean nationwide cohort study. Stroke 2017;48(11):2984-2990

19 Noubiap JJ, Feteh VF, Middeldorp ME, et al. A meta-analysis of clinical risk factors for stroke in anticoagulant-naïve patients with atrial fibrillation. Europace 2021;23(10):1528-1538

20 Chao TF, Lip GYH, Lin YJ, et al. Age threshold for the use of nonvitamin $\mathrm{K}$ antagonist oral anticoagulants for stroke prevention in patients with atrial fibrillation: insights into the optimal assessment of age and incident comorbidities. Eur Heart J 2019;40(19): 1504-1514

21 Kim TH, Yang PS, Yu HT, et al. Age threshold for ischemic stroke risk in atrial fibrillation. Stroke 2018;49(08):1872-1879

22 Nielsen PB, Larsen TB, Skjøth F, Overvad TF, Lip GY. Stroke and thromboembolic event rates in atrial fibrillation according to different guideline treatment thresholds: a nationwide cohort study. Sci Rep 2016;6:27410

23 Chang TY, Lip GYH, Chen SA, Chao TF. Importance of risk reassessment in patients with atrial fibrillation in guidelines: assessing risk as a dynamic process. Can J Cardiol 2019;35(05): 611-618

24 Chao TF, Lip GYH, Liu CJ, et al. Relationship of aging and incident comorbidities to stroke risk in patients with atrial fibrillation. J Am Coll Cardiol 2018;71(02):122-132

25 Chao TF, Chiang CE, Chen TJ, Lip GYH, Chen SA. Reassessment of risk for stroke during follow-up of patients with atrial fibrillation. Ann Intern Med 2019;170(09):663-664 
26 Yoon M, Yang PS, Jang E, et al. Dynamic changes of CHA2DS2VASc score and the risk of ischaemic stroke in asian patients with atrial fibrillation: a nationwide cohort study. Thromb Haemost 2018;118(07):1296-1304

27 Fauchier L, Bodin A, Bisson A, et al. Incident comorbidities, aging and the risk of stroke in 608,108 patients with atrial fibrillation: a nationwide analysis. J Clin Med 2020;9(04):9

28 Chao TF, Liao JN, Tuan TC, et al. Incident co-morbidities in patients with atrial fibrillation initially with a CHA2DS2-VASc score of 0 (males) or 1 (females): implications for reassessment of stroke risk in initially 'low-risk' patients. Thromb Haemost 2019;119(07):1162-1170

29 Borre ED, Goode A, Raitz G, et al. Predicting thromboembolic and bleeding event risk in patients with non-valvular atrial fibrillation: a systematic review. Thromb Haemost 2018;118(12): 2171-2187

30 Proietti M, Romiti GF, Vitolo M, Potpara TS, Boriani G, Lip GYH. Comparison of HAS-BLED and ORBIT bleeding risk scores in AF patients treated with NOACs: a report from the ESC-EHRA EORPAF general long-term registry. Eur Heart J Qual Care Clin Outcomes 2021. Doi: 10.1093/ehjqcco/qcab069

31 Guo Y, Zhu H, Chen Y, Lip GYH. Comparing bleeding risk assessment focused on modifiable risk factors only versus validated bleeding risk scores in atrial fibrillation. Am J Med 2018;131(02): 185-192

32 Chao TF, Lip GYH, Lin YJ, et al. Incident risk factors and major bleeding in patients with atrial fibrillation treated with oral anticoagulants: a comparison of baseline, follow-up and delta HAS-BLED scores with an approach focused on modifiable bleeding risk factors. Thromb Haemost 2018;118(04):768-777

33 Guo Y, Lane DA, Wang L, et al; mAF-App II Trial Investigators. Mobile health technology to improve care for patients with atrial fibrillation. J Am Coll Cardiol 2020;75(13):1523-1534

34 Guo Y, Lane DA, Chen Y, Lip GYHmAF-App II Trial investigators. Regular bleeding risk assessment associated with reduction in bleeding outcomes: the mAFA-II randomized trial. Am J Med 2020;133(10):1195.e2-1202.e2

35 Chao TF, Chan YH, Chiang CE, et al. Continuation or discontinuation of oral anticoagulants after HAS-BLED scores increase in patients with atrial fibrillation. Clin Res Cardiol 2021. Doi: 10.1007/s00392-021-01816-z

36 Chao TF, Chan YH, Tuan TC, et al. Should oral anticoagulants still be prescribed to patients with atrial fibrillation with a single stroke risk factor but at high bleeding risk? a nationwide cohort study. Eur Heart J Qual Care Clin Outcomes 2021. Doi: 10.1093/ehjqcco/qcab050

37 Lip GYH, Collet JP, de Caterina R, et al. Antithrombotic therapy in atrial fibrillation associated with valvular heart disease: executive summary of a joint consensus document from the European Heart Rhythm Association (EHRA) and European Society of Cardiology Working Group on Thrombosis, Endorsed by the ESC Working Group on Valvular Heart Disease, Cardiac Arrhythmia Society of Southern Africa (CASSA), Heart Rhythm Society (HRS), Asia Pacific Heart Rhythm Society (APHRS), South African Heart (SA Heart) Association and Sociedad Latinoamericana de Estimulación Cardíaca y Electrofisiología (SOLEACE). Thromb Haemost 2017;117(12):2215-2236

38 Connolly S, Pogue J, Hart R, et al; ACTIVE Writing Group of the ACTIVE Investigators. Clopidogrel plus aspirin versus oral anticoagulation for atrial fibrillation in the Atrial fibrillation Clopidogrel Trial with Irbesartan for prevention of Vascular Events (ACTIVE W): a randomised controlled trial. Lancet 2006;367 (9526):1903-1912

39 Connolly SJ, Ezekowitz MD, Yusuf S, et al; RE-LY Steering Committee and Investigators. Dabigatran versus warfarin in patients with atrial fibrillation. N Engl J Med 2009;361(12): 1139-1151
40 Connolly SJ, Eikelboom J, Joyner C, et al; AVERROES Steering Committee and Investigators. Apixaban in patients with atrial fibrillation. N Engl J Med 2011;364(09):806-817

41 Granger CB, Alexander JH, McMurray JJ, et al; ARISTOTLE Committees and Investigators. Apixaban versus warfarin in patients with atrial fibrillation. N Engl J Med 2011;365(11):981-992

42 Chao TF, Chen SA, Lip GYH. Recommendations on stroke prevention for patients having a $\mathrm{CHA}_{2} \mathrm{DS}_{2}$-VASc score of 1 (males) or 2 (females) in 2019 atrial fibrillation guidelines. Trends Cardiovasc Med 2019;29(07):427-428

43 Chao TF, Liu CJ, Wang KL, et al. Should atrial fibrillation patients with 1 additional risk factor of the CHA2DS2-VASc score (beyond sex) receive oral anticoagulation? J Am Coll Cardiol 2015;65(07): 635-642

44 Chao TF, Wang KL, Liu CJ, et al. Age threshold for increased stroke risk among patients with atrial fibrillation: a nationwide cohort study from Taiwan. J Am Coll Cardiol 2015;66(12):1339-1347

45 ChaoTF, Chiang CE, Liao JN, Chen TJ, Lip GYH, Chen SA. Comparing the effectiveness and safety of nonvitamin $\mathrm{K}$ antagonist oral anticoagulants and warfarin in elderly asian patients with atrial fibrillation: a nationwide cohort study. Chest 2020;157(05): 1266-1277

46 Kuo L, Chan YH, Liao JN, Chen SA, Chao TF. Stroke and bleeding risk assessment in atrial fibrillation: where are we now? Korean Circ J 2021;51(08):668-680

47 Lee SR, Lee YS, Park JS, et al. Label adherence for non-vitamin K antagonist oral anticoagulants in a prospective cohort of Asian patients with atrial fibrillation. Yonsei Med J 2019;60(03): 277-284

48 Lee SR, Choi EK, Han KD, Jung JH, Oh S, Lip GYH. Optimal rivaroxaban dose in Asian patients with atrial fibrillation and normal or mildly impaired renal function. Stroke 2019;50(05): 1140-1148

49 Cheng WH, Chao TF, Lin YJ, et al. Low-dose rivaroxaban and risks of adverse events in patients with atrial fibrillation. Stroke 2019; 50(09):2574-2577

50 Chan YH, Chao TF, Chen SW, et al. Off-label dosing of non-vitamin $\mathrm{K}$ antagonist oral anticoagulants and clinical outcomes in Asian patients with atrial fibrillation. Heart Rhythm 2020;17(12): 2102-2110

51 Yu HT, Yang PS, Jang E, et al. Label adherence of direct oral anticoagulants dosing and clinical outcomes in patients with atrial fibrillation. J Am Heart Assoc 2020;9(12):e014177

52 Lee SR, Choi EK, Park SH, et al. Off-label underdosed apixaban use in Asian patients with non-valvular atrial fibrillation. Eur Heart J Cardiovasc Pharmacother 2021;7(05):415-423

53 Kim D, Yang PS, Jang E, et al. The optimal drug adherence to maximize the efficacy and safety of non-vitamin $\mathrm{K}$ antagonist oral anticoagulant in real-world atrial fibrillation patients. Europace 2020;22(04):547-557

$54 \mathrm{Kim} \mathrm{H}$, Lee YS, Kim TH, et al. A prospective survey of the persistence of warfarin or NOAC in nonvalvular atrial fibrillation: a COmparison study of Drugs for symptom control and complication prEvention of Atrial Fibrillation (CODE-AF). Korean J Intern Med (Korean Assoc Intern Med) 2020;35(01):99-108

55 Guo Y, Kotalczyk A, Imberti JF, Wang Y, Lip GYH. Quality indicators in the management of elderly Chinese patients with atrial fibrillation: a report from the Optimal Thromboprophylaxis in Elderly Chinese Patients with Atrial Fibrillation (ChiOTEAF) registry. Eur Heart J Qual Care Clin Outcomes 2021. Doi: 10.1093/ehjqcco/qcab057

56 Pandey AK, Xu K, Zhang L, et al. Lower versus standard INR targets in atrial fibrillation: a systematic review and metaanalysis of randomized controlled trials. Thromb Haemost 2020;120(03):484-494

57 Berwaerts J, Dijkhuizen RS, Robb OJ, Webster J. Prediction of functional outcome and in-hospital mortality after admission 
with oral anticoagulant-related intracerebral hemorrhage. Stroke 2000;31(11):2558-2562

58 Wan Y, Heneghan C, Perera R, et al. Anticoagulation control and prediction of adverse events in patients with atrial fibrillation: a systematic review. Circ Cardiovasc Qual Outcomes 2008;1(02): 84-91

59 Proietti M, Lane DA, Lip GY. Relation of the SAMe-TT2R2 score to quality of anticoagulation control and thromboembolic events in atrial fibrillation patients: observations from the SPORTIF trials. Int J Cardiol 2016;216:168-172

60 Chan PH, Hai JJ, Chan EW, et al. Use of the SAMe-TT2R2 score to predict good anticoagulation control with warfarin in chinese patients with atrial fibrillation: relationship to ischemic stroke incidence. PLoS One 2016;11(03):e0150674

61 Roldán V, Cancio S, Gálvez J, et al. The SAMe-TT2R2 score predicts poor anticoagulation control in AF patients: a prospective 'realworld' inception cohort study. Am J Med 2015;128(11): $1237-1243$

62 Gallego P, Roldán V, Marin F, et al. SAMe-TT2R2 score, time in therapeutic range, and outcomes in anticoagulated patients with atrial fibrillation. Am J Med 2014;127(11):1083-1088

63 Apostolakis S, Sullivan RM, Olshansky B, Lip GYH. Factors affecting quality of anticoagulation control among patients with atrial fibrillation on warfarin: the $S A M e-T_{2} R_{2}$ score. Chest 2013;144(05):1555-1563

64 Phrommintikul A, Nathisuwan S, Gunaparn S, et al; TREATS-AF Study Group. Prospective randomised trial examining the impact of an educational intervention versus usual care on anticoagulation therapy control based on an SAMe- $\mathrm{TT}_{2} \mathrm{R}_{2}$ scoreguided strategy in anticoagulant-naïve Thai patients with atrial fibrillation (TREATS-AF): a study protocol. BMJ Open 2021;11 (10):e051987

65 Wang KL, Lip GY, Lin SJ, Chiang CE. Non-vitamin K antagonist oral anticoagulants for stroke prevention in Asian patients with nonvalvular atrial fibrillation: meta-analysis. Stroke 2015;46 (09):2555-2561

66 Liu T, Hui J, Hou YY, et al. Meta-analysis of efficacy and safety of low-intensity warfarin therapy for East Asian patients with nonvalvular atrial fibrillation. Am J Cardiol 2017;120(09):1562-1567

67 Kodani E, Atarashi H, Inoue H, Okumura K, Yamashita TJRHYTHM Registry Investigators. Target intensity of anticoagulation with warfarin in Japanese patients with valvular atrial fibrillation - subanalysis of the J-RHYTHM registry. Circ J 2015; 79(02):325-330

68 Chao TF, Guo Y. Should we adopt a standard international normalized ratio range of 2.0 to 3.0 for Asian patients with atrial fibrillation? An appeal for evidence-based management, not eminence-based recommendations. Thromb Haemost 2020; 120(03):366-368

69 Pritchett RV, Bem D, Turner GM, et al. Improving the prescription of oral anticoagulants in atrial fibrillation: a systematic review. Thromb Haemost 2019;119(02):294-307

70 Hwang J, Han S, Bae HJ, et al. NOAC adherence of patients with atrial fibrillation in the real world: dosing frequency matters? Thromb Haemost 2020;120(02):306-313

71 Jones NR, Crawford W, Yang Y, Hobbs FDR, Taylor CJ, Petrou S. A systematic review of economic aspects of service interventions to increase anticoagulation use in atrial fibrillation. Thromb Haemost 2021

72 Ruff CT, Giugliano RP, Braunwald E, et al. Comparison of the efficacy and safety of new oral anticoagulants with warfarin in patients with atrial fibrillation: a meta-analysis of randomised trials. Lancet 2014;383(9921):955-962

73 Chao TF, Chen SA, Ruff CT, et al. Clinical outcomes, edoxaban concentration, and anti-factor Xa activity of Asian patients with atrial fibrillation compared with non-Asians in the ENGAGE AFTIMI 48 trial. Eur Heart J 2019;40(19):1518-1527
74 Chan YH, Lee HF, Chao TF, et al. Real-world comparisons of direct oral anticoagulants for stroke prevention in asian patients with non-valvular atrial fibrillation: a systematic review and metaanalysis. Cardiovasc Drugs Ther 2019;33(06):701-710

75 Chao TF, Liu CJ, Lin YJ, et al. Oral anticoagulation in very elderly patients with atrial fibrillation: a nationwide cohort study. Circulation 2018;138(01):37-47

76 Lee SR, Choi EK, Park CS, et al. Direct oral anticoagulants in patients with nonvalvular atrial fibrillation and low body weight. J Am Coll Cardiol 2019;73(08):919-931

77 Lee SR, Lee HJ, Choi EK, et al. Direct oral anticoagulants in patients with atrial fibrillation and liver disease. J Am Coll Cardiol 2019;73(25):3295-3308

78 Kuo L, Chao TF, Liu CJ, et al. Liver cirrhosis in patients with atrial fibrillation: would oral anticoagulation have a net clinical benefit for stroke prevention? J Am Heart Assoc 2017;6(06):6

79 Kwon S, Lee SR, Choi EK, et al. Non-vitamin K antagonist oral anticoagulants in very elderly east Asians with atrial fibrillation: a nationwide population-based study. Am Heart J 2020; 229:81-91

80 Tsai CT, Liao JN, Chen SJ, Jiang YR, Chen TJ, Chao TF. Non-vitamin K antagonist oral anticoagulants versus warfarin in AF patients $\geq$ 85 years. Eur J Clin Invest 2021;51(06):e13488

81 Yao X, Shah ND, Sangaralingham LR, Gersh BJ, Noseworthy PA. Non-vitamin $\mathrm{K}$ antagonist oral anticoagulant dosing in patients with atrial fibrillation and renal dysfunction. J Am Coll Cardiol 2017;69(23):2779-2790

82 Pokorney SD, Peterson ED, Piccini JP. When less is not more. J Am Coll Cardiol 2017;69:2791-2793

83 Wang KL, Lopes RD, Patel MR, et al. Efficacy and safety of reduced-dose non-vitamin $\mathrm{K}$ antagonist oral anticoagulants in patients with atrial fibrillation: a meta-analysis of randomized controlled trials. Eur Heart J 2019;40(19):1492-1500

84 Cheng WH, Chan YH, Liao JN, Kuo L, Chen SA, Chao TF. Optimal management of anticoagulation therapy in Asian patients with atrial fibrillation. Circ J 2021;85(08):1245-1253

85 Chan YH, Chao TF, Lee HF, et al. Impacts of different renal function estimation formulas on dosing of DOACs and clinical outcomes. J Am Coll Cardiol 2020;76(15):1808-1810

86 Chan YH, Lee HF, Wang CL, et al. Comparisons of rivaroxaban following different dosage criteria (ROCKET AF or J-ROCKET AF trials) in Asian patients with atrial fibrillation. J Am Heart Assoc 2019;8(21):e013053

87 Angiolillo DJ, Goodman SG, Bhatt DL, et al. Antithrombotic therapy in patients with atrial fibrillation undergoing percutaneous coronary intervention: a North American Perspective2016 update. Circ Cardiovasc Interv 2016;9(11):9

88 Park J, Choi EK, Han KD, et al. Temporal trends in prevalence and antithrombotic treatment among Asians with atrial fibrillation undergoing percutaneous coronary intervention: a nationwide Korean population-based study. PLoS One 2019;14(01):e0209593

89 Kwon S, Jung JH, Choi EK, et al. Impact of non-vitamin $\mathrm{K}$ antagonist oral anticoagulants on the change of antithrombotic regimens in patients with atrial fibrillation undergoing percutaneous coronary intervention. Korean Circ J 2021;51(05): 409-422

90 Vitolo M, Javed S, Capodanno D, Rubboli A, Boriani G, Lip GYH. Antithrombotic treatment in atrial fibrillation patients undergoing percutaneous coronary interventions: focus on stent thrombosis. Expert Rev Cardiovasc Ther 2020;18(09):587-600

91 Kim HK, Tantry US, Smith SC Jr, et al. The East Asian paradox: an updated position statement on the challenges to the current antithrombotic strategy in patients with cardiovascular disease. Thromb Haemost 2021;121(04):422-432

92 Dewilde WJ, Oirbans T, Verheugt FW, et al; WOEST study investigators. Use of clopidogrel with or without aspirin in patients taking oral anticoagulant therapy and undergoing 
percutaneous coronary intervention: an open-label, randomised, controlled trial. Lancet 2013;381(9872):1107-1115

93 Gibson CM, Mehran R, Bode C, et al. Prevention of bleeding in patients with atrial fibrillation undergoing PCI. N Engl J Med 2016;375(25):2423-2434

94 Cannon CP, Bhatt DL, Oldgren J, et al; RE-DUAL PCI Steering Committee and Investigators. Dual antithrombotic therapy with dabigatran after PCI in atrial fibrillation. N Engl J Med 2017;377 (16):1513-1524

95 Lopes RD, Heizer G, Aronson R, et al; AUGUSTUS Investigators. Antithrombotic therapy after acute coronary syndrome or PCI in atrial fibrillation. N Engl J Med 2019;380(16):1509-1524

96 Vranckx P, Valgimigli M, Eckardt L, et al. Edoxaban-based versus vitamin $\mathrm{K}$ antagonist-based antithrombotic regimen after successful coronary stenting in patients with atrial fibrillation (ENTRUST-AF PCI): a randomised, open-label, phase 3b trial. Lancet 2019;394(10206):1335-1343

97 Oldgren J, Steg PG, Hohnloser SH, et al. Dabigatran dual therapy with ticagrelor or clopidogrel after percutaneous coronary intervention in atrial fibrillation patients with or without acute coronary syndrome: a subgroup analysis from the RE-DUAL PCI trial. Eur Heart J 2019;40(19):1553-1562

98 Steffel J, Collins R, Antz M, et al. 2021 European Heart Rhythm Association practical guide on the use of non-vitamin K antagonist oral anticoagulants in patients with atrial fibrillation. Europace 2021;23(10):1612-1676

99 Lee SR, Rhee TM, Kang DY, Choi EK, Oh S, Lip GYH. Meta-analysis of oral anticoagulant monotherapy as an antithrombotic strategy in patients with stable coronary artery disease and nonvalvular atrial fibrillation. Am J Cardiol 2019;124(06):879-885

100 Yasuda S, Kaikita K, Akao M, et al; AFIRE Investigators. Antithrombotic therapy for atrial fibrillation with stable coronary disease. N Engl J Med 2019;381(12):1103-1113

101 Di Biase L, Burkhardt JD, Santangeli P, et al. Periprocedural stroke and bleeding complications in patients undergoing catheter ablation of atrial fibrillation with different anticoagulation management: results from the Role of Coumadin in Preventing Thromboembolism in Atrial Fibrillation (AF) Patients Undergoing Catheter Ablation (COMPARE) randomized trial. Circulation 2014;129(25):2638-2644

102 Calkins H, Hindricks G, Cappato R, et al. 2017 HRS/EHRA/ ECAS/APHRS/SOLAECE expert consensus statement on catheter and surgical ablation of atrial fibrillation. Heart Rhythm 2017;14 (10):e275-e444

103 Murakawa Y, Yamane T, Goya M, et al; Japanese Heart Rhythm Society Members. Influence of substrate modification in catheter ablation of atrial fibrillation on the incidence of acute complications: analysis of 10795 procedures in J-CARAF Study 20112016. J Arrhythm 2018;34(04):435-440

104 Hohnloser SH, Camm AJ. Safety and efficacy of dabigatran etexilate during catheter ablation of atrial fibrillation: a metaanalysis of the literature. Europace 2013;15(10):1407-1411

105 Cappato R, Marchlinski FE, Hohnloser SH, et al; VENTURE-AF Investigators. Uninterrupted rivaroxaban vs. uninterrupted vitamin $\mathrm{K}$ antagonists for catheter ablation in non-valvular atrial fibrillation. Eur Heart J 2015;36(28):1805-1811

106 Calkins H, Willems S, Gerstenfeld EP, et al; RE-CIRCUIT Investigators. Uninterrupted dabigatran versus warfarin for ablation in atrial fibrillation. N Engl J Med 2017;376(17):1627-1636

107 Kirchhof P, Haeusler KG, Blank B, et al. Apixaban in patients at risk of stroke undergoing atrial fibrillation ablation. Eur Heart J 2018;39(32):2942-2955

108 Hohnloser SH, Camm J, Cappato R, et al. Uninterrupted edoxaban vs. vitamin $\mathrm{K}$ antagonists for ablation of atrial fibrillation: the ELIMINATE-AF trial. Eur Heart J 2019;40(36):3013-3021

109 Zhao Y, Lu Y, Qin Y. A meta-analysis of randomized controlled trials of uninterrupted periprocedural anticoagulation strategy in patients undergoing atrial fibrillation catheter ablation. Int J Cardiol 2018;270:167-171

110 Cardoso R, Knijnik L, Bhonsale A, et al. An updated meta-analysis of novel oral anticoagulants versus vitamin $\mathrm{K}$ antagonists for uninterrupted anticoagulation in atrial fibrillation catheter ablation. Heart Rhythm 2018;15(01):107-115

111 Nakamura K, Naito S, Sasaki T, et al. Uninterrupted vs. interrupted periprocedural direct oral anticoagulants for catheter ablation of atrial fibrillation: a prospective randomized singlecentre study on post-ablation thrombo-embolic and haemorrhagic events. Europace 2019;21(02):259-267

112 Yu HT, Shim J, Park J, et al. When is it appropriate to stop nonvitamin $\mathrm{K}$ antagonist oral anticoagulants before catheter ablation of atrial fibrillation? A multicentre prospective randomized study. Eur Heart J 2019;40(19):1531-1537

113 Nogami A, Harada T, Sekiguchi Y, et al; ABRIDGE-J (ABlation peRIoperative DabiGatran in use Envisioning in Japan) Investigators. Safety and efficacy of minimally interrupted dabigatran vs uninterrupted warfarin therapy in adults undergoing atrial fibrillation catheter ablation: a randomized clinical trial. JAMA Netw Open 2019;2(04):e191994

114 Takahashi N, Mukai Y, Kimura T, et al; KYU-RABLE Investigators. Efficacy and safety of uninterrupted periprocedural edoxaban in patients undergoing catheter ablation for atrial fibrillation - the prospective KYU-RABLE study. Circ J 2019; 83(10):2017-2024

115 Schiele F, van Ryn J, Canada K, et al. A specific antidote for dabigatran: functional and structural characterization. Blood 2013;121(18):3554-3562

116 Pollack CV Jr, Reilly PA, Eikelboom J, et al. Idarucizumab for dabigatran reversal. N Engl J Med 2015;373(06):511-520

117 Pollack CV Jr, Reilly PA, van Ryn J, et al. Idarucizumab for dabigatran reversal - full cohort analysis. N Engl J Med 2017; 377(05):431-441

118 Eikelboom JW, van Ryn J, Reilly P, et al. Dabigatran reversal with idarucizumab in patients with renal impairment. J Am Coll Cardiol 2019;74(14):1760-1768

119 Fanikos J, Murwin D, Gruenenfelder F, et al. Global use of idarucizumab in clinical practice: outcomes of the RE-VECTO surveillance program. Thromb Haemost 2020;120(01):27-35

120 Lu G, DeGuzman FR, Hollenbach SJ, et al. A specific antidote for reversal of anticoagulation by direct and indirect inhibitors of coagulation factor Xa. Nat Med 2013;19(04):446-451

121 Siegal DM, Curnutte JT, Connolly SJ, et al. Andexanet alfa for the reversal of factor Xa inhibitor activity. N Engl J Med 2015;373 (25):2413-2424

122 Connolly SJ, Crowther M, Eikelboom JW, et al; ANNEXA-4 Investigators. Full study report of andexanet alfa for bleeding associated with factor Xa inhibitors. N Engl J Med 2019;380(14): 1326-1335

123 Chang TY, Chan YH, Chiang CE, et al. Risks and outcomes of gastrointestinal malignancies in anticoagulated atrial fibrillation patients experiencing gastrointestinal bleeding: a nationwide cohort study. Heart Rhythm 2020;17(10):1745-1751

124 Yu HT, Kim TH, Uhm JS, et al. Clinical significance of hematuria in atrial fibrillation with oral anticoagulation therapy. Circ J 2017; 81(02):158-164

125 Glikson M, Wolff R, Hindricks G, et al; ESC Scientific Document Group. EHRA/EAPCI expert consensus statement on catheterbased left atrial appendage occlusion - an update. Europace 2019. Doi: 10.1093/europace/euz258

126 Whitlock RP, Belley-Cote EP, Paparella D, et al; LAAOS III Investigators. Left atrial appendage occlusion during cardiac surgery to prevent stroke. N Engl J Med 2021;384(22):2081-2091

127 Holmes DR, Reddy VY, Turi ZG, et al; PROTECT AF Investigators. Percutaneous closure of the left atrial appendage versus warfarin therapy for prevention of stroke in patients with atrial 
fibrillation: a randomised non-inferiority trial. Lancet 2009;374 (9689):534-542

128 Holmes DR Jr, Kar S, Price MJ, et al. Prospective randomized evaluation of the Watchman Left Atrial Appendage Closure device in patients with atrial fibrillation versus long-term warfarin therapy: the PREVAIL trial. J Am Coll Cardiol 2014;64(01): $1-12$

129 Reddy VY, Holmes D, Doshi SK, Neuzil P, Kar S. Safety of percutaneous left atrial appendage closure: results from the Watchman Left Atrial Appendage System for Embolic Protection in Patients with AF (PROTECT AF) clinical trial and the Continued Access Registry. Circulation 2011;123(04):417-424

130 Holmes DR Jr, Doshi SK, Kar S, et al. Left atrial appendage closure as an alternative to warfarin for stroke prevention in atrial fibrillation: a patient-level meta-analysis. J Am Coll Cardiol 2015;65(24):2614-2623

131 Osmancik P, Tousek P, Herman D, et al; PRAGUE-17 Investigators. Interventional left atrial appendage closure vs novel anticoagulation agents in patients with atrial fibrillation indicated for long-term anticoagulation (PRAGUE-17 study). Am Heart J 2017; 183:108-114

132 Osmancik P, Herman D, Neuzil P, et al; PRAGUE-17 Trial Investigators. Left atrial appendage closure versus direct oral anticoagulants in high-risk patients with atrial fibrillation. J Am Coll Cardiol 2020;75(25):3122-3135

133 Boersma LV, Ince H, Kische S, et al; EWOLUTION Investigators. Efficacy and safety of left atrial appendage closure with WATCHMAN in patients with or without contraindication to oral anticoagulation: 1-year follow-up outcome data of the EWOLUTION trial. Heart Rhythm 2017;14(09):1302-1308

134 Mazzone P, D’Angelo G, Regazzoli D, et al. Percutaneous left atrial appendage closure with WATCHMAN ${ }^{\mathrm{TM}}$ device: peri-procedural and mid-term outcomes from the TRAPS registry. J Interv Card Electrophysiol 2018;52(01):47-52

135 Boersma LV, Ince H, Kische S, et al; following investigators and institutions participated in the EWOLUTION study. Evaluating real-world clinical outcomes in atrial fibrillation patients receiving the WATCHMAN left atrial appendage closure technology: final 2-year outcome data of the EWOLUTION trial focusing on history of stroke and hemorrhage. Circ Arrhythm Electrophysiol 2019;12(04):e006841

136 Aonuma K, Yamasaki H, Nakamura M, et al. Percutaneous WATCHMAN left atrial appendage closure for Japanese patients with nonvalvular atrial fibrillation at increased risk of thromboembolism - first results from the SALUTE trial. Circ J 2018;82 (12):2946-2953

137 Phillips KP, Santoso T, Sanders P, et al. Left atrial appendage

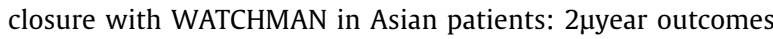
from the WASP registry. Int J Cardiol Heart Vasc 2019; 23:100358

138 Bajaj NS, Parashar A, Agarwal S, et al. Percutaneous left atrial appendage occlusion for stroke prophylaxis in nonvalvular atrial fibrillation: a systematic review and analysis of observational studies. JACC Cardiovasc Interv 2014;7(03):296-304

139 Badheka AO, Chothani A, Mehta K, et al. Utilization and adverse outcomes of percutaneous left atrial appendage closure for stroke prevention in atrial fibrillation in the United States: influence of hospital volume. Circ Arrhythm Electrophysiol 2015;8(01):42-48

140 Lempereur M, Aminian A, Freixa X, et al. Device-associated thrombus formation after left atrial appendage occlusion: a systematic review of events reported with the Watchman, the Amplatzer Cardiac Plug and the Amulet. Catheter Cardiovasc Interv 2017;90(05):E111-E121

141 Fauchier L, Cinaud A, Brigadeau F, et al. Device-related thrombosis after percutaneous left atrial appendage occlusion for atrial fibrillation. J Am Coll Cardiol 2018;71(14):1528-1536
142 Fauchier L, Cinaud A, Brigadeau F, et al. Major adverse events with percutaneous left atrial appendage closure in patients with atrial fibrillation. J Am Coll Cardiol 2019;73(20):2638-2640

143 Sedaghat A, Vij V, Al-Kassou B, et al. Device-related thrombus after left atrial appendage closure: data on thrombus characteristics, treatment strategies, and clinical outcomes from the EUROC-DRT-registry. Circ Cardiovasc Interv 2021;14(05): e010195

144 Holmes DR, Reddy VY, Buchbinder M, et al. The Assessment of the Watchman Device in Patients Unsuitable for Oral Anticoagulation (ASAP-TOO) trial. Am Heart J 2017;189:68-74

145 Reddy VY, Akehurst RL, Armstrong SO, Amorosi SL, Beard SM, Holmes DR Jr. Time to cost-effectiveness following stroke reduction strategies in AF: warfarin versus NOACs versus LAA closure.J Am Coll Cardiol 2015;66(24):2728-2739

146 Reddy VY, Akehurst RL, Gavaghan MB, Amorosi SL, Holmes DR Jr. Cost-effectiveness of left atrial appendage closure for stroke reduction in atrial fibrillation: analysis of pooled, 5-year, longterm data. J Am Heart Assoc 2019;8(13):e011577

147 Pathak RK, Elliott A, Middeldorp ME, et al. Impact of CARDIOrespiratory FITness on arrhythmia recurrence in obese individuals with atrial fibrillation: the CARDIO-FIT study. J Am Coll Cardiol 2015;66(09):985-996

148 Pathak RK, Middeldorp ME, Lau DH, et al. Aggressive risk factor reduction study for atrial fibrillation and implications for the outcome of ablation: the ARREST-AF cohort study. J Am Coll Cardiol 2014;64(21):2222-2231

149 Pathak RK, Middeldorp ME, Meredith M, et al. Long-term effect of goal-directed weight management in an atrial fibrillation cohort: a long-term follow-up study (LEGACY). J Am Coll Cardiol 2015;65(20):2159-2169

$150 \mathrm{Lim}$ C, Kim TH, Yu HT, et al. Effect of alcohol consumption on the risk of adverse events in atrial fibrillation: from the COmparison study of Drugs for symptom control and complication prEvention of Atrial Fibrillation (CODE-AF) registry. Europace 2021;23 (04):548-556

151 Joung B. Risk factor management for atrial fibrillation. Korean Circ J 2019;49(09):794-807

$152 \mathrm{Kim} \mathrm{TH}$, Yang PS, Yu HT, et al. Effect of hypertension duration and blood pressure level on ischaemic stroke risk in atrial fibrillation: nationwide data covering the entire Korean population. Eur Heart J 2019;40(10):809-819

153 Kim D, Yang PS, Kim TH, et al. Ideal blood pressure in patients with atrial fibrillation. J Am Coll Cardiol 2018;72(11):1233-1245

154 Lee SS, Ae Kong K, Kim D, et al. Clinical implication of an impaired fasting glucose and prehypertension related to new onset atrial fibrillation in a healthy Asian population without underlying disease: a nationwide cohort study in Korea. Eur Heart J 2017;38 (34):2599-2607

155 Lee SR, Choi EK, Ahn HJ, Han KD, Oh S, Lip GYH. Association between clustering of unhealthy lifestyle factors and risk of newonset atrial fibrillation: a nationwide population-based study. Sci Rep 2020;10(01):19224

156 Lee JH, Yang PS, Yu HT, et al. Association of cardiovascular health and incident atrial fibrillation in elderly population. Heart 2021. Doi: 10.1136/heartjnl-2020-318858

157 Wang TJ, Parise H, Levy D, et al. Obesity and the risk of new-onset atrial fibrillation. JAMA 2004;292(20):2471-2477

158 Baek YS, Yang PS, Kim TH, et al. Associations of abdominal obesity and new-onset atrial fibrillation in the general population. J Am Heart Assoc 2017;6(06):6

159 Abed HS, Wittert GA, Leong DP, et al. Effect of weight reduction and cardiometabolic risk factor management on symptom burden and severity in patients with atrial fibrillation: a randomized clinical trial. JAMA 2013;310(19):2050-2060

160 Lim YM, Yang PS, Jang E, et al. Body mass index variability and long-term risk of new-onset atrial fibrillation in the general 
population: a Korean nationwide cohort study. Mayo Clin Proc 2019;94(02):225-235

161 Middeldorp ME, Pathak RK, Meredith M, et al. PREVEntion and regReSsive Effect of weight-loss and risk factor modification on Atrial Fibrillation: the REVERSE-AF study. Europace 2018;20 (12):1929-1935

162 Kang SH, Choi EK, Han KD, et al. Underweight is a risk factor for atrial fibrillation: a nationwide population-based study. Int J Cardiol 2016;215:449-456

163 Lee HJ, Choi EK, Han KD, et al. Bodyweight fluctuation is associated with increased risk of incident atrial fibrillation. Heart Rhythm 2020;17(03):365-371

164 Overvad TF, Rasmussen LH, Skjøth F, Overvad K, Lip GY, Larsen TB. Body mass index and adverse events in patients with incident atrial fibrillation. Am J Med 2013;126(07):640. e9-640.e17

165 Proietti M, Guiducci E, Cheli P, Lip GY. Is there an obesity paradox for outcomes in atrial fibrillation? A systematic review and meta-analysis of non-vitamin $\mathrm{K}$ antagonist oral anticoagulant trials. Stroke 2017;48(04):857-866

166 Lee SR, Choi EK, Jung JH, et al. Body mass index and clinical outcomes in asian patients with atrial fibrillation receiving oral anticoagulation. Stroke 2021;52(02):521-530

167 Larsson SC, Drca N, Wolk A. Alcohol consumption and risk of atrial fibrillation: a prospective study and dose-response metaanalysis. J Am Coll Cardiol 2014;64(03):281-289

168 Pisters R, Lane DA, Nieuwlaat R, de Vos CB, Crijns HJ, Lip GY. A novel user-friendly score (HAS-BLED) to assess 1-year risk of major bleeding in patients with atrial fibrillation: the Euro Heart Survey. Chest 2010;138(05):1093-1100

169 Overvad TF, Rasmussen LH, Skjøth F, et al. Alcohol intake and prognosis of atrial fibrillation. Heart 2013;99(15):1093-1099

170 Lee SR, Choi EK, Jung JH, Han KD, Oh S, Lip GYH. Lower risk of stroke after alcohol abstinence in patients with incident atrial fibrillation: a nationwide population-based cohort study. Eur Heart J 2021. Doi: 10.1093/eurheartj/ehab315

171 Voskoboinik A, Kalman JM, De Silva A, et al. Alcohol abstinence in drinkers with atrial fibrillation. N Engl J Med 2020;382(01): 20-28

172 Choi YJ, Han KD, Choi EK, et al. Alcohol abstinence and the risk of atrial fibrillation in patients with newly diagnosed type 2 diabetes mellitus: a nationwide population-based study. Diabetes Care 2021;44:1393-1401

173 Chamberlain AM, Agarwal SK, Folsom AR, et al. Smoking and incidence of atrial fibrillation: results from the Atherosclerosis Risk in Communities (ARIC) study. Heart Rhythm 2011;8(08): 1160-1166

174 Zhu W, Yuan P, Shen Y, Wan R, Hong K. Association of smoking with the risk of incident atrial fibrillation: a meta-analysis of prospective studies. Int J Cardiol 2016;218:259-266

175 Kwon S, Kim TJ, Choi EK, et al. Predictors of ischemic stroke for low-risk patients with atrial fibrillation: a matched case-control study. Heart Rhythm 2021;18(05):702-708

176 Lee SR, Choi EK, Jung JH, Han KD, Oh S, Lip GYH. Smoking cessation after diagnosis of new-onset atrial fibrillation and the risk of stroke and death. J Clin Med 2021;10(11):10

177 Kim IS, Yang PS, Lee J, et al. Long-term exposure of fine particulate matter air pollution and incident atrial fibrillation in the general population: a nationwide cohort study. Int J Cardiol 2019;283:178-183

178 Kim IS, Yang PS, Jang E, et al. Long-term $\mathrm{PM}_{2.5}$ exposure and the clinical application of machine learning for predicting incident atrial fibrillation. Sci Rep 2020;10(01):16324

179 Mozaffarian D, Furberg CD, Psaty BM, Siscovick D. Physical activity and incidence of atrial fibrillation in older adults: the cardiovascular health study. Circulation 2008;118(08):800-807

180 Hegbom F, Stavem K, Sire S, Heldal M, Orning OM, Gjesdal K. Effects of short-term exercise training on symptoms and quality of life in patients with chronic atrial fibrillation. Int J Cardiol 2007;116(01):86-92

181 Osbak PS, Mourier M, Kjaer A, Henriksen JH, Kofoed KF, Jensen GB. A randomized study of the effects of exercise training on patients with atrial fibrillation. Am Heart J 2011;162(06): 1080-1087

182 Faselis C, Kokkinos P, Tsimploulis A, et al. Exercise capacity and atrial fibrillation risk in veterans: a cohort study. Mayo Clin Proc 2016;91(05):558-566

183 Jin MN, Yang PS, Song C, et al. Physical activity and risk of atrial fibrillation: a nationwide cohort study in general population. Sci Rep 2019;9(01):13270

184 Abdulla J, Nielsen JR. Is the risk of atrial fibrillation higher in athletes than in the general population? A systematic review and meta-analysis. Europace 2009;11(09):1156-1159

185 Ahn HJ, Lee SR, Choi EK, et al. Association between exercise habits and stroke, heart failure, and mortality in Korean patients with incident atrial fibrillation: a nationwide population-based cohort study. PLoS Med 2021;18(06):e1003659

186 Lim J, Lee SR, Choi EK, et al. Exercise and the risk of dementia in patients with newly diagnosed atrial fibrillation: a nationwide population-based study. J Clin Med 2021;10(14):10

187 Elias P, Poterucha TJ, Jain SS, et al. The prognostic value of electrocardiogram at presentation to emergency department in patients with COVID-19. Mayo Clin Proc 2020;95(10): 2099-2109

188 Musikantow DR, Turagam MK, Sartori S, et al. Atrial fibrillation in patients hospitalized with COVID-19: incidence, predictors, outcomes, and comparison to influenza. JACC Clin Electrophysiol 2021;7(09):1120-1130

189 Lip GYH, Genaidy A, Tran G, Marroquin P, Estes C. Incident atrial fibrillation and its risk prediction in patients developing COVID19: a machine learning based algorithm approach. Eur J Intern Med 2021;91:53-58

190 Romiti GF, Corica B, Lip GYH, Proietti M. Prevalence and impact of atrial fibrillation in hospitalized patients with COVID-19: a systematic review and meta-analysis. J Clin Med 2021;10(11):10

191 Bikdeli B, Madhavan MV, Jimenez D, et al; Global COVID-19 Thrombosis Collaborative Group, Endorsed by the ISTH, NATF, ESVM, and the IUA, Supported by the ESC Working Group on Pulmonary Circulation and Right Ventricular Function. COVID19 and thrombotic or thromboembolic disease: implications for prevention, antithrombotic therapy, and follow-up: JACC stateof-the-art review. J Am Coll Cardiol 2020;75(23):2950-2973

192 Emren ZY, Şenöz O, Erseçgin A, Emren SV. Evaluation of bleeding rate and time in therapeutic range in patients using warfarin before and during the COVID-19 pandemic-warfarin treatment in COVID-19. Clin Appl Thromb Hemost 2021; 27:10760296211021495

193 Papakonstantinou PE, Borovac JA, Gąsecka A, et al. Anticoagulation therapy in non-valvular atrial fibrillation in the COVID-19 era: is it time to reconsider our therapeutic strategy? Eur J Prev Cardiol 2021. Doi: 10.1093/eurjpc/zwab021

194 Li X, Zuo C, Lu W, et al. Evaluation of Remote pharmacist-led outpatient service for geriatric patients on rivaroxaban for nonvalvular atrial fibrillation during the COVID-19 pandemic. Front Pharmacol 2020;11:1275

195 Bikdeli B, Madhavan MV, Gupta A, et al; Global COVID-19 Thrombosis Collaborative Group. Pharmacological agents targeting thromboinflammation in COVID-19: review and implications for future research. Thromb Haemost 2020;120(07): 1004-1024

196 Fumagalli S, Trevisan C, Del Signore S, et al; GeroCovid Working Group. COVID-19 and atrial fibrillation in older patients: does oral anticoagulant therapy provide a survival benefit?-An insight from the GeroCovid Registry Thromb Haemost 2021

197 Denas G, Gennaro N, Ferroni E, et al. Reduction in all-cause mortality in COVID-19 patients on chronic oral anticoagulation: 
a population-based propensity score matched study. Int J Cardiol 2021;329:266-269

198 Nadkarni GN, Lala A, Bagiella E, et al. Anticoagulation, bleeding, mortality, and pathology in hospitalized patients with COVID19. J Am Coll Cardiol 2020;76(16):1815-1826

199 Rivera-Caravaca JM, Buckley BJR, Harrison SL, et al. Direct-acting oral anticoagulants use prior to COVID-19 diagnosis and associations with 30-day clinical outcomes. Thromb Res 2021;205:1-7

200 Talasaz AH, Sadeghipour P, Kakavand H, et al. Recent randomized trials of antithrombotic therapy for patients with COVID-19: JACC state-of-the-art review. J Am Coll Cardiol 2021;77(15):1903-1921

201 Lawler PR, Goligher EC, Berger JS, et al; ATTACC Investigators ACTIV-4a Investigators REMAP-CAP Investigators. Therapeutic anticoagulation with heparin in noncritically ill patients with Covid-19. N Engl J Med 2021;385(09):790-802

202 Bikdeli B, Talasaz AH, Rashidi F, et al. Intermediate-dose versus standard-dose prophylactic anticoagulation in patients with COVID-19 admitted to the intensive care unit: 90-day results from the INSPIRATION randomized trial. Thromb Haemost 2021

203 Sadeghipour P, Talasaz AH, Rashidi F, et al; INSPIRATION Investigators. Effect of intermediate-dose vs standard-dose prophylactic anticoagulation on thrombotic events, extracorporeal membrane oxygenation treatment, or mortality among patients with COVID-19 admitted to the intensive care unit: the INSPIRATION randomized clinical trial. JAMA 2021;325(16): $1620-1630$

204 Lopes RD, de Barros E Silva PGM, Furtado RHM, et al; ACTION Coalition COVID-19 Brazil IV Investigators. Therapeutic versus prophylactic anticoagulation for patients admitted to hospital with COVID-19 and elevated D-dimer concentration (ACTION): an open-label, multicentre, randomised, controlled trial. Lancet 2021;397(10291):2253-2263

205 Gerotziafas GT, Catalano M, Theodorou Y, et al; Scientific Reviewer Committee. The COVID-19 pandemic and the need for an integrated and equitable approach: an international expert consensus paper. Thromb Haemost 2021;121(08): 992-1007

206 Ford GA, Hargroves D, Lowe D, et al. Targeted atrial fibrillation (AF) detection in COVID-19 vaccination clinics. Eur Heart J Qual Care Clin Outcomes 2021;7(06):526-528

207 Elalamy I, Gerotziafas G, Alamowitch S, et al; Scientific Reviewer Committee. SARS-CoV-2 vaccine and thrombosis: an expert consensus on vaccine-induced immune thrombotic thrombocytopenia. Thromb Haemost 2021;121(08):982-991 